\title{
WestVirginiaUniversity
}

THE RESEARCH REPOSITORY @ WVU

Graduate Theses, Dissertations, and Problem Reports

2010

\section{Essays on the public economics of health}

Rachel L. Mathers

West Virginia University

Follow this and additional works at: https://researchrepository.wvu.edu/etd

\section{Recommended Citation}

Mathers, Rachel L., "Essays on the public economics of health" (2010). Graduate Theses, Dissertations, and Problem Reports. 3091.

https://researchrepository.wvu.edu/etd/3091

This Dissertation is protected by copyright and/or related rights. It has been brought to you by the The Research Repository @ WVU with permission from the rights-holder(s). You are free to use this Dissertation in any way that is permitted by the copyright and related rights legislation that applies to your use. For other uses you must obtain permission from the rights-holder(s) directly, unless additional rights are indicated by a Creative Commons license in the record and/ or on the work itself. This Dissertation has been accepted for inclusion in WVU Graduate Theses, Dissertations, and Problem Reports collection by an authorized administrator of The Research Repository @ WVU.

For more information, please contact researchrepository@mail.wvu.edu. 


\title{
ESSAYS ON THE PUBLIC ECONOMICS OF HEALTH
}

\author{
Rachel L. Mathers \\ Dissertation submitted to the \\ College of Business and Economics \\ at West Virginia University \\ in partial fulfillment of the requirements \\ for the degree of \\ Doctor of Philosophy \\ in \\ Economics \\ Russell S. Sobel, Ph.D., Chair
Christopher J. Coyne, Ph.D.
Santiago M. Pinto, Ph.D.
Tami Gurley-Calvez, Ph.D.
Claudia R. Williamson, Ph.D. \\ Department of Economics \\ Morgantown, West Virginia \\ 2010
}

Keywords: AIDS, Bureaucracy; Collective Action; Female Genital Mutilation; Institutions; Public Goods; Secondary Effects; Skin Cancer

Copyright 2010 Rachel L. Mathers 


\section{ABSTRACT \\ Essays on the Public Economics of Health}

\section{Rachel L. Mathers}

This dissertation explores three important health issues, utilizing the tools provided by economics to provide new insight into areas of research typically the parlance of those in medical fields of study. The integration of economic theory into existing literature on health issues provides a more detail-rich explanation of health policy and corresponding health outcomes. This dissertation applies economic theory to the health topics of skin cancer, Female Genital Mutilation (FGM), and AIDS. There are five chapters included in this dissertation, beginning with an introduction in Chapter 1 . Chapter 2 addresses the skin cancer paradox, specifically analyzing the relationship between National Cancer Institute spending and melanoma incidence. Chapter 3 provides the economics of FGM, addressing both the persistence of the practice over time and avenues for the change or elimination of the practice. Chapter 4 estimates the degree of publicness of AIDS prevention spending using an empirical median voter demand model. Finally, Chapter 5 summarizes the major findings and policy implications of the preceding chapters and offers concluding remarks. 


\section{ACKNOWLEDGEMENTS}

I would like to thank those who helped me make it through graduate school without losing too much of my sanity. At the top of that list are my parents, Gail and Kyle Mathers; without your support and encouragement, I wouldn't have embarked on such a journey in the first place. Dad, you have been a source of strength and calm through the worst circumstances, and I can never express just how much those moments helped me stay the course. Mom, you have always been my confidant, source of comfort, and everenthusiastic cheerleader. Without our phone calls, I surely would not have had the courage to endure the many road blocks on the way to completing this dissertation. To you both, I am forever grateful for your guidance and love. To my brother, Curtis Mathers, thank you for putting up with me. You have amazing talent in music and academics, and I cannot wait to see where those talents take you in life.

To my dissertation committee, I thank each of you for your helpful comments and the wisdom you've offered. Russell Sobel, thank you for being my dissertation advisor. Your Public Choice class was what first inspired me to take this route for my dissertation topic, and your practical, wise advice was incredibly helpful throughout my graduate career. Santiago Pinto, thank you for believing in me when I arrived at West Virginia University. I would not have been able to work my way through the first semester of classes without your patience and willingness to answer my questions without ever admonishing me for not already knowing the answers. Tami Gurley-Calvez, thank you for your optimism, advice, and for teaching me econometrics. You are an inspiration. Claudia Williamson, thank you for being a wonderful co-author and friend. I learned a lot during our collaborations for the Charles G. Koch Foundation, and I look forward to many more projects in the future.

My dissertation committee would not have been complete without Christopher J. Coyne. I want to thank him, especially, for being a mentor, co-author, and friend. You encouraged me to follow my passion and research the topics I truly care about. Your humor and wisdom have been more than important for my success as a graduate student and, more importantly, my success as a budding scholar. Thank you for reminding me why I came to graduate school.

Lastly, I have several friends to thank for their enduring support through this process. Christa Jensen, you have been my dearest graduate school friend. I feel so fortunate to have met a friend like you. You were my favorite study buddy and Zumba classmate, and I will always appreciate your honesty, a trait difficult to find. Michael Cook, thank you for being a friend for life, for making me laugh when I want to cry, and for providing inspiration for the investigation of skin cancer in this dissertation.

To each of you mentioned above, thank you for making me the person I am today. This work is dedicated to all of you. 


\section{TABLE OF CONTENTS}

Chapter 1:

Introduction.......................................................................................1

Chapter 2:

Learn or Burn? The Economics of the Skin Cancer Paradox

2.1 Introduction.............................................................

2.2 Literature and Background.....................................................9

2.3 Theoretical Explanations for the Skin Cancer Paradox....................14

2.4 Conclusion.................................................................26

Chapter 3:

A Rational Ritual: The Economics of Female Genital Mutilation

3.1 Introduction.............................................................29

3.2 FGM-Background and Stylized Facts.................................33

3.3 Why Does FGM Persist?......................................................................................36

3.4 Why and How do FGM Practices Change?..............................................46

3.5 Conclusion...............................................................53

Chapter 4:

Empirical Evidence on the Publicness of AIDS Prevention

4.1 Introduction.....................................................................55

4.2 Literature Review...........................................................57

4.3 Methodology.............................................................59

4.4 Empirical Results........................................................66

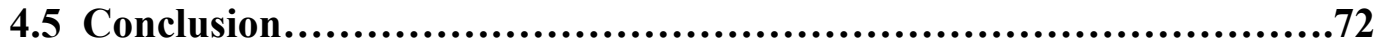

Chapter 5:

Conclusion..............................................................................75

References.......................................................................80

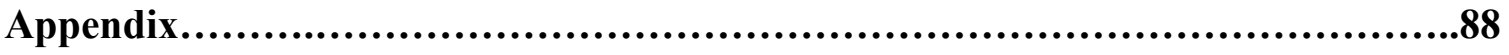




\section{LIST OF TABLES}

Table 4.1 Weighted Least Squares Regression Results..........................68 Appendix Tables:

Table 2.1 Data Definitions and Sources.........................................88

Table 2.2 Summary Statistics, using the observations 1975-2004...............89

Table 2.3 Empirical Results (Using DDNCI), 1977-2004........................90

Table 2.4 Empirical Results (Using NCI), 1975-2004........................92 


\section{LIST OF FIGURES}

Figure 2.1 The Skin Cancer Laffer Curve........................................10

Figure 2.2 Plot of Per Capita NCI Spending and Melanoma Incidence Rates....13

Figure 3.1 The Identity Game..................................................42

Appendix Figures:

Figure 2.1 Graph of Melanoma Incidence and Mortality for Population:

Age 20-49...............................................................93

Figure 2.2 Hypotheses Explaining the Skin Cancer Paradox.....................94

Figure 4.1 Descriptive Statistics.............................................95

Figure 4.2 Variable Definitions and Data Sources...............................96

Figure 4.3 Pooled OLS Regression Results....................................97

Figure 4.4 Random-effects Regression Results.................................98

Figure 4.5 Publicness Results Comparison......................................99

Figure 4.6 Cross-Section Regression Results.................................100 


\section{Chapter 1}

\section{Introduction}

The aim of health economics is to apply economic concepts to topics related to health, and the scope of this field is large, including topics as diverse as health policy (and the market for health care and insurance) and analysis of specific diseases or treatment methods using behavioral economics. Though economists have explored a wide variety of inquiries into health-related topics, the relative youth of health economics leaves much to be garnered from the application of economics to health. Public economics is particularly relevant to this task, as much research in health economics focuses on health policy. Likewise, economic development and political economy offer important insights into areas of analysis once regarded as the domain of medical researchers and practitioners alone.

One of the most important contributions of economics to the study of health concepts is a better understanding of why economic actors behave as they do. In other words, economists have offered analysis of the behavior of patients, doctors, and others involved in health issues (Musgrove 2004). For instance, Fuchs (1986) explained how information affects health incentives and behavioral outcomes, which have economic implications as well. These behavioral inquiries are critical in determining the appropriate information dispersion necessary to produce desirable outcomes. One application of this type of analysis is to prevention strategies, such as the ideal method of information delivery and the content and scope of such informational campaigns. 
Analysis of health market failures is yet another contribution of public economics to the study of health outcomes. For example, public goods and their corresponding externalities, whether positive or negative, create the potential for market failure, especially when the externalities are large and it is difficult to prevent free riding (Samuelson 1954). Therefore, health goods with characteristics of public goods (i.e. nonrivalry and non-excludability) present unique challenges to the healthcare industry that can be further understood with thorough economic analysis.

Understanding institutional economics and how the "rules of the game" shape incentives and outcomes is of particular importance in the study of the economics of health (for example, Williamson 2000; North 1990). The incentives created by the healthcare institutions have important implications for health outcomes, both in terms of the health of patients and the efficiency of the health sector. These issues are relevant not only for how best to structure the healthcare sector in the United States, but also help inform health interventions abroad. For example, any intervention in a foreign country stands to benefit from a thorough understanding of the institutional mechanisms at play (both formal and informal), as the outcome of particular intervention strategies hinges critically on the compatibility of intervention strategies with local institutions (Coyne 2007).

In addition to the concepts discussed previously, the literature of bureaucracy is also relevant in the analysis of health policy and corresponding outcomes. The unique structural characteristics of bureaucracy create incentives that can lead to perverse outcomes (Niskanen 1968). As Niskanen (1971) points out, the incentives faced by bureaucrats are such that budget maximization is the means for bureaucratic utility 
maximization, implying a lack of incentive to operate efficiently. Further, Mises (1944) highlights the inherent stumbling block of bureaucracies - they lack a profit motive, which is the cornerstone in the private producer's incentive to continuously search for mechanisms to improve efficiency and to innovate. Lacking a clear measure of public sector efficiency or efficacy, the outcomes of the public health sector may fall below anticipated results. This dissertation extends this framework, applying the concepts discussed above to the health topics of skin cancer, Female Genital Mutilation (FGM), and AIDS.

The second chapter of this dissertation addresses the skin cancer paradox, specifically analyzing the relationship between National Cancer Institute spending and melanoma incidence. Logic dictates that government spending directed towards skin cancer research and prevention would result in a lower incidence rate of skin cancer. However, the pattern observed over time is an increase in both the incidence rate and the per capita spending of the National Cancer Institute. This chapter applies concepts from the secondary effects literature and bureaucracy literature to provide economic rationale for this paradoxical relationship.

The secondary effects of prevention spending and the resulting perceived costs and benefits of sun safety are elemental in this paradoxical relationship. A public policy with heavy emphasis on sun safety and preventative measures, in addition to the broad range of sun protective items, has not been effective in reducing the incidence rate of melanoma. The secondary effects associated with an emphasis on safety and exaggerated reports of success in the "war on cancer" can result in an undercalculation of the true costs of sun exposure and lead to more risky behavior. 
Another explanation for this relationship draws from the literature on bureaucracy. The incentives faced by bureaucracies are such that a policy of ineffective but ever-increasing spending contributes to these perverse outcomes. In their current form, these bureaucracies provide incentives encouraging budget maximization, leading, in the extreme, to mismanagement of funds and the fraudulent or exaggerated research results. Additionally, the capture of cancer bureaucracies by drug company special interests leads to incentives promoting research into costly new drug treatments and a lack of extensive exploration of alternative, and often less expensive, treatment avenues. Finally, the lack of feedback mechanisms to measure the efficiency of cancer bureaucracies results in a lack of incentives to pursue skin cancer research and prevention in an efficient manner. The insights offered by this economic analysis provide serious implications for public policy pertaining to skin cancer prevention and research.

The third chapter of this dissertation focuses on female genital mutilation (hereafter FGM), which involves the partial or complete excision of external female genitalia (primarily the clitoris and labia majora and minora) and other damage to the female genital organs (World Health Organization 2008). Largely absent from the existing literature is the application of rational choice analysis to the practice of FGM, though there are exceptions. Mackie (1996) provides a 'convention account' for the existence of and parallels between the practices of infibulation and footbinding. Chesnokova and Vaithianathan (2007) provide an empirical analysis of female genital cutting and marriage in Burkina Faso. However, neither analysis formulates an economic theory for the persistence and change of FGM. This research provides the first economic theory of the mechanisms of FGM persistence and change, as most queries into FGM 
have been conducted in the anthropological or sociological framework. The rational choice framework, including insights from game theory, serves as the basis for this analysis.

The central exploration of this chapter is focused on the rational foundations for a ritual, which is often viewed as something “...inherited from an untraceable path which has no rational meaning and lies within the realm of untouchable sensitivity of traditional people" (Toubia 1993: 4). In contrast to the view that FGM is an irrational practice, the central argument of this chapter is that FGM is, indeed, a rational ritual. Specifically, this chapter uses a rational choice analysis of the practice of FGM to answer the following questions: (1) why does the practice of FGM persist? and (2) why and how does the practice of FGM change? Answering these questions is pertinent for both health and human rights concerns. Game theory foundations are utilized to provide a model for answering both of these important questions. Finally, an examination of the methods of intervention and change in the practice lends evidence that formal laws alone are not enough to eliminate the practice of FGM. Instead, economic rationale suggests that the key for change is the creation of common knowledge around the change or cessation of the practice of FGM.

Chapter four of this dissertation estimates the degree of publicness of AIDS prevention spending using an empirical median voter demand model. Measured on a range from zero (purely public) to one (purely private), this calculation provides an estimation of the externalities associated with AIDS prevention. The characteristics of many AIDS prevention efforts have characteristics that appear public in nature. For example, a large part of AIDS prevention spending comes in the form of education 
spending. A public service announcement, poster campaign, or public speaker would all be relatively public in nature. This is especially true in the sense that many of the educational programs aimed at AIDS prevention are likely to be fairly nonrival in consumption (i.e. one person's consumption doesn't interfere with another's consumption) and nonexcludable (i.e. it is difficult to exclude individuals from consuming the good), which are the key attributes of a public good.

This chapter demonstrates that there are significant spillovers to AIDS prevention spending and examines the implications of these spillovers. Results from this analysis suggest that markets are relatively efficient, as AIDS prevention is more private than public in nature. However, the results also indicate that, though more private than public, over one-third of AIDS prevention spending is public in nature, implying that there are significant spillover benefits associated with this spending. The broader implications of these results are also discussed in this chapter.

The overall theme and focus of this dissertation is the public economics of health. Contributions to existing literature include an economic explanation for the skin cancer paradox, an economic theory for the persistence and change of the FGM practice, and a measure of the publicness of AIDS prevention spending. Each of these chapters contributes to several strands of literature, including health economics, public economics, and political economy, among others. Chapter five summarizes the contributions, findings, and policy implications of chapters two through five and provides concluding remarks. 


\section{CHAPTER 2}

\section{Learn or Burn? The Economics of the Skin Cancer Paradox}

\subsection{Introduction}

Has government spending on skin cancer prevention reduced the skin cancer incidence rate? In the United States, more than one million cases of skin cancer are diagnosed each year, ranking skin cancer as the most common cancer in the country. ${ }^{1}$ One in five Americans will be afflicted with the disease in their lifetime, and more than $90 \%$ of these cases are caused by sun exposure. ${ }^{2}$ Despite Coppertone's 1980 development of sunscreen which protects against both UVA and UVB sun rays, the incidence of skin cancer has increased dramatically over the past thirty-five years. ${ }^{3}$ Specifically, melanoma (one common type of skin cancer) doubled in its rate of incidence over this period. ${ }^{4}$ Meanwhile, the National Cancer Institute, an extension of the National Institutes of Health, has more than doubled their per capita spending over this same period in their efforts aimed at prevention education and research into better treatments and a cure for cancer.

Logic dictates that the amount spent on skin cancer prevention should be inversely related to the skin cancer incidence rate, yet there is a positive relationship between the two. This paradox is the focus of this paper. The tools provided by economics will be applied to explain the various reasons for the positive relationship

\footnotetext{
${ }^{1} \mathrm{http}: / /$ www.skincancer.org/skincancer-facts.php

${ }^{2}$ Ibid.

${ }^{3}$ http://lib.bioinfo.pl/meid:281943

${ }^{4}$ http://www.melanomacenter.org/basics/statistics.html
} 
between government spending on skin cancer prevention and the incidence rate of skin cancer. Given the aforementioned statistics, it appears that skin cancer incidence displays a relationship similar to the relationship exhibited between tax rates and tax revenues in the backward-bending portion of the Laffer Curve. In this portion of the Laffer Curve, as the tax rate is lowered, tax revenues increase. It is quite possible, even probable, that individuals have increased their sun exposure over time because of the lower probability of contracting skin cancer due to medical advances in sun protection and sunburn treatment and because of overstated beliefs in the effectiveness of prevention efforts. Skin cancer is unique from many other forms of cancer in that the link between individual behavior and the risk of incidence or death from skin cancer is strong to quite strong, thus "public education of primary and secondary prevention measures should play a vital role in skin cancer prevention efforts" (Stryker, Solky, and Emmons 2005). However, due to an increase in risky behavior, the result is a much higher rate of incidence, in spite of improved sun protection technologies and increased spending for government-funded skin cancer research and prevention campaigns. Increased sun exposure increases the risk of sunburn and, as a corollary, the risk of skin cancer, as the risk of developing skin cancer doubles with five or more sunburns over the course of an individual's lifetime. ${ }^{5}$ The economic way of thinking can provide insight into this counterintuitive relationship.

This research contributes to the existing literature in two key ways: (1) applying the Laffer Curve logic to health care policy and outcomes, (2) providing two theoretical explanations for the skin cancer paradox, the first being secondary effects and the second

\footnotetext{
${ }^{5}$ http://www.skincancer.org/skincancer-facts.php
} 
being bureaucracy effects. Much of the existing literature pertaining to skin cancer is in medical journals, and no research in the economics literature examines skin cancer in this nature. The purpose of this paper is to fill this gap. Economic analysis can resolve the apparent skin cancer paradox, providing insight into the incentives individuals face when making cancer-related behavioral choices and the incentives faced by those working for a government-funded cancer institute.

The layout of the paper is as follows. Section 2.2 offers a review existing literature, including a discussion of the skin cancer paradox and its relationship to the Laffer Curve. Section 2.3 describes the two theoretical explanations for the skin cancer paradox. The economic rationale of secondary effects is examined first, followed by an economic analysis of bureaucratic organization and its impact on the fight against skin cancer. Finally, Section 2.4 offers a conclusion and resulting policy implications.

\subsection{Literature and Background}

This paper is grounded in two strands of literature. The first of these is the Laffer Curve literature or, more broadly, the secondary effects literature. In the "prohibitive range" of the original Laffer Curve (Laffer 2004), a decrease in the tax rate will result in an increase in tax revenues, as individuals will have greater incentives to work. In other words, in this range the increased incentives to work more than outweigh the lower tax rate applied to each dollar earned. Individuals are working more than enough additional hours to make up for the lower percentage in taxes taken from each dollar, thus more tax revenues are the result. This is the range of interest for the study of the skin cancer 
paradox. Figure 2.1 displays the Skin Cancer Laffer Curve, developed by altering Laffer's original curve - relating tax rates and tax revenues - to reflect the relationship between National Cancer Institute spending and incidence rates for melanoma.

\section{Figure 2.1: The Skin Cancer Laffer Curve}

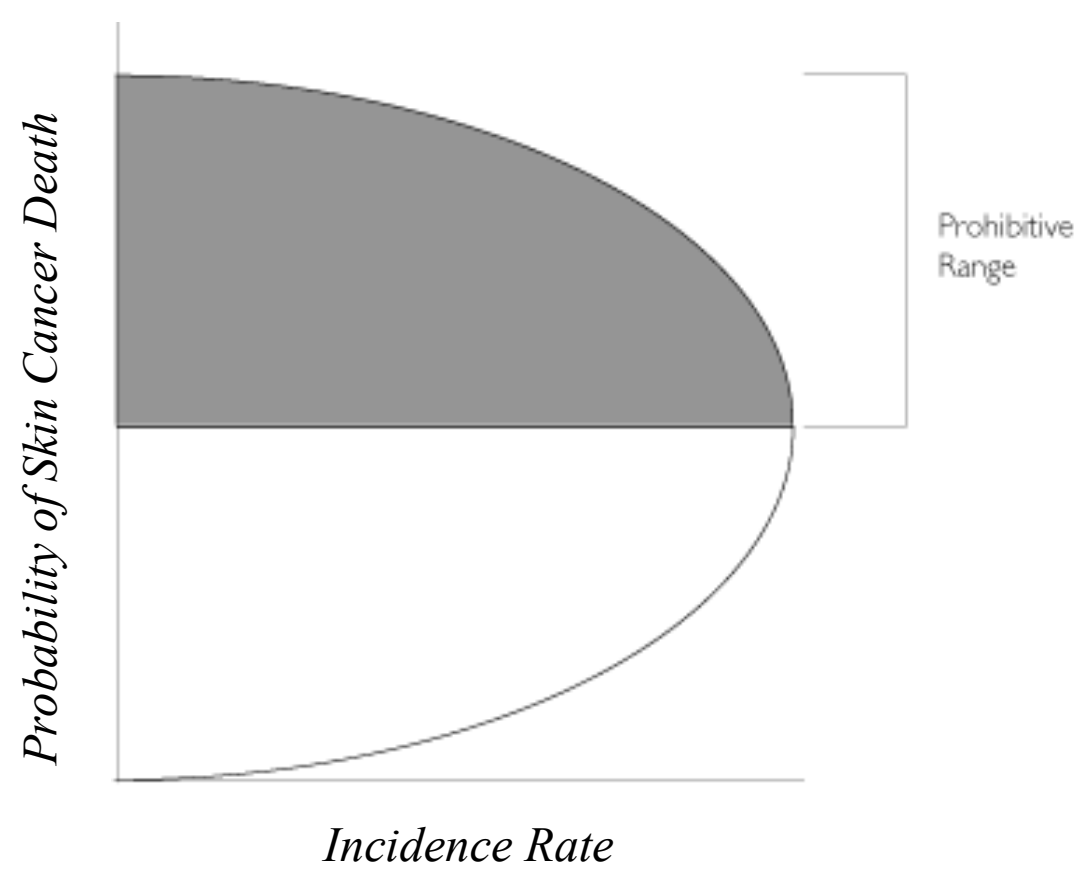

In other words, government spending for cancer research and prevention lowers the probability of death associated with risky sun behavior, resulting in an increase in risky behavior large enough to increase the incidence rate in spite of the lower probability of death. Put another way, the behavioral response of individuals more than offsets the 
intended outcome of cancer-related government spending (see shaded area in Figure 2.1). Thus, an institute created to decrease the incidence rate of cancer inadvertently does the opposite by lowering the expected cost of risky behavior.

The Laffer Curve logic has been applied to many different issues (see, for example, Viscusi 1985; Shmanske 2002; Stroup 1998; Clark and Lee 1996; Lensink and White 1999). The same logic can be applied to the skin cancer paradox. The methodology required for this research involves defining an equation representing the relationship between the probability of contracting skin cancer and the number of cases of skin cancer diagnoses per year. The following equation will be used as a proxy for the paradox presented in this paper:

$$
\mathrm{N}_{\mathrm{D}}=\mathrm{P}_{\mathrm{D}} * \mathrm{~N}_{\mathrm{O}}
$$

where $N_{D}$ represents the number of skin cancer diagnoses per annum, $P_{D}$ represents the probability of contracting skin cancer, and $\mathrm{N}_{O}$ represents the number of people overexposed to UVA and UVB sun rays. If the theory outlined is correct, one would expect to see an increase in both $\mathrm{N}_{\mathrm{O}}$ and $\mathrm{N}_{\mathrm{D}}$, even though $\mathrm{P}_{\mathrm{D}}$ has decreased. With the government's increased focus on skin cancer prevention and ever-improving protection products and medical intervention, $\mathrm{P}_{\mathrm{D}}$ decreased. However, it is likely that individuals also increased their sun exposure due to the lower risk of contracting skin cancer. With such things as advances in sun protection technology, increases in prevention campaigns, and improvements in minimizing the visible effects of sun damage to the skin, the expected cost of engaging in risky sun exposure decreases. Thus, the comparison of costs and benefits yields a new equilibrium of risky behavior, and we observe an increase in 
the number of individuals overexposed to the sun's rays and an increase in the overall number of skin cancer diagnoses per year. The available data support this theory. ${ }^{6}$ Figure 2 includes a plot of the National Cancer Institute (hereafter NCI) spending per capita and the incidence rate of melanoma, the most common form of skin cancer, for the years $1975-2004 .^{7}$

${ }^{6}$ Appendix Tables 2.3 and 2.4 display the results of an empirical analysis of the skin cancer paradox (with a data description provided in Table 2.1 and summary statistics included in Table 2.2). These results indicate that NCI spending has had no statistically significant effect on skin cancer incidence, offering empirical evidence of the impotence of government spending for cancer-related research and prevention education in impacting skin cancer incidence rates. Taking into account that there is no measure to account for the effect of sunscreen, protective clothing, or treatment breakthroughs on melanoma incidence, the empirical analysis offered here is potentially overstating the effects of NCI spending on melanoma incidence. In other words, if sunscreen innovations could be included in the regressions in any meaningful way, this would account for some of the reduction one would have expected to observe in melanoma incidence rates. Considering this in the analysis of the effectiveness of NCI spending, one could reason that this spending could have had a significantly positive effect on incidence rates - increasing rather than decreasing them - that is being masked by the omission of a sunscreen measure, rather than the insignificant effect witnessed in the regression results presented herein. If anything, this strengthens the skin cancer paradox. Regardless, the amount of money funneled into NCI projects has not had the expected effect of decreasing incidence rates.

${ }^{7}$ Appendix Figure 1 graphs the skin cancer mortality rate and incidence rate for the population age 20-49. This graph demonstrates the expected results of decreased mortality rate and increased incidence rate over time. Note that graphing strictly this age group controls for the effect of generations of individuals exposed to sun damage well before the available NCI budget data or new sunscreen improvements (i.e. this eliminates the impact of high incidence rates among those overexposed before NCI programs evolved). 


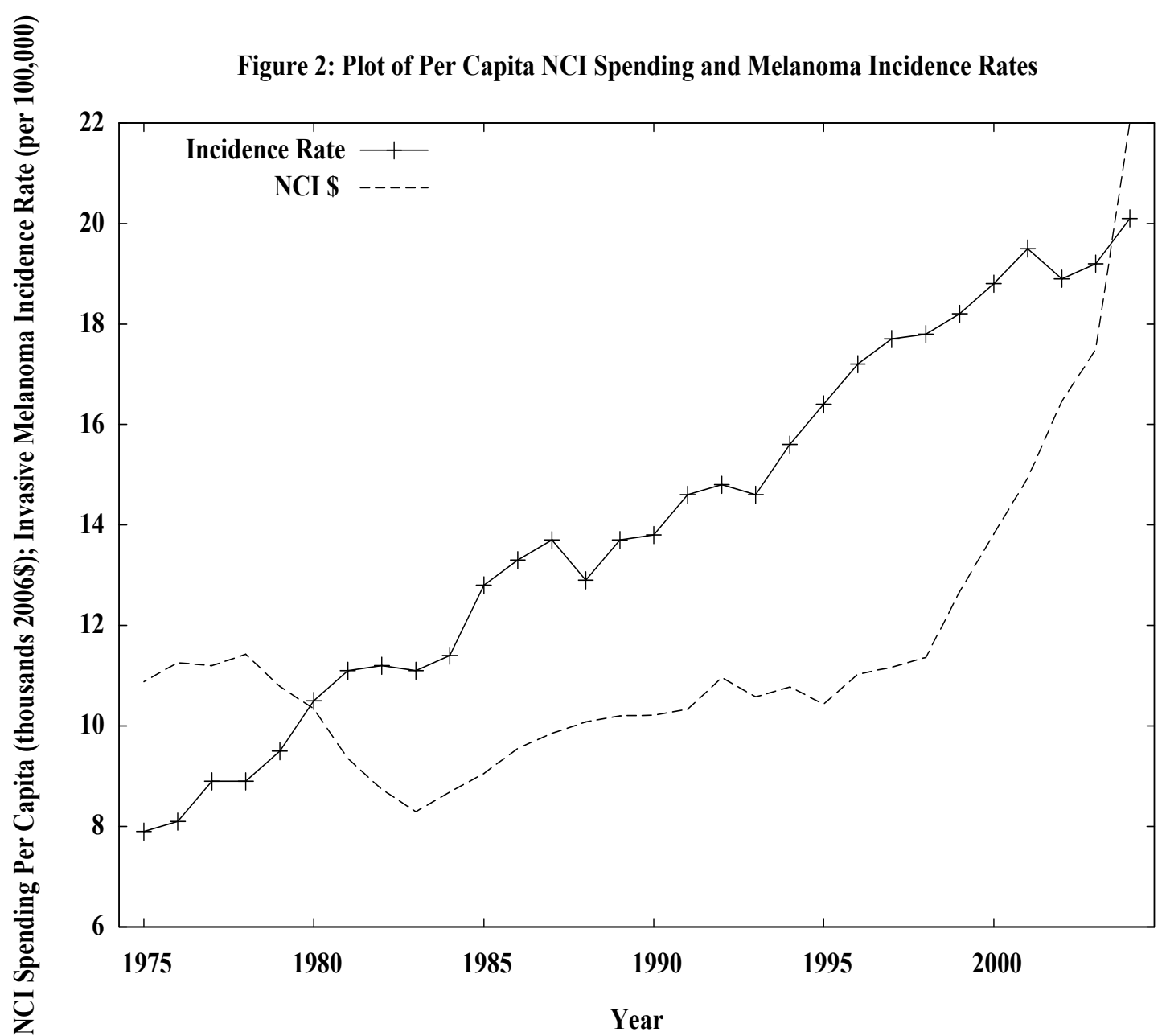

One clear counterargument to the skin cancer paradox is the hypothesis that increased use of skin cancer screening or improved detection may be the true cause of the drastic increase in incidence rates. However, Beddingfield (2003) provides evidence to the contrary and "strongly argues against the idea that the increase in incidence of melanoma is only due to early detection of thin lesions or biologically benign lesions" (448). The reasoning behind this assertion is longitudinal evidence of an increase in all stages of localized melanoma. In spite of this finding, Beddingfield (2003) does assert 
that early detection has played a role in the increase in the survival rate, offering further support for the secondary effects hypothesis.

Another potential issue is that this outcome is being driven by the increasing popularity of tanning beds, which contribute to skin cancer. ${ }^{8}$ A study by El Ghissassi et al. (2009) finds that use of tanning beds before age 30 increases skin cancer risk by 75 percent. Specifically, one may assume that women are driving up the incidence rate, given that a study by Geller et al. (2002: 1) found that "Girls were far more likely than boys to report tanning bed use (14.4 vs 2.4 ), and older girls (ages $15-18$ ) were far more likely than younger girls (ages 12-14) to report tanning bed use (24.6\% vs 4.7)." However, empirical results (included in Appendix Tables 2.3 and 2.4) indicate that the tanning bed effect is not driving the observed relationship between NCI spending and skin cancer incidence.

\subsection{Theoretical Explanations for the Skin Cancer Paradox}

At first glance, the skin cancer paradox may seem counterintuitive, but further investigation into secondary effects and bureaucracy lends rationale to these findings. If the NCI is achieving their intended goal, an ever-increasing allocation of funds to this goal would be correlated with lower melanoma incidence rates. However, Figure 2.2 indicates that the intended goals aren't being achieved. Not only has the incidence rate increased over time, but NCI spending has had no significant effect on the incidence rate.

\footnotetext{
${ }^{8}$ Additional regressions (included in columns 2 and 3 of Appendix Tables 2.3 and 2.4) serve as a means of determining whether the increasing use of tanning beds by females has skewed the effect of NCI funding on melanoma incidence rates. These additional regressions also serve as a robustness check on the original results. These results suggest that the tanning bed effect for females has not played a role in NCI spending effectiveness. NCI spending is insignificant in affecting the male or female melanoma incidence rate.
} 
Looking first at secondary effects, one possible explanation for this result is that the government's focus on a sun safety prevention approach has resulted in a false and overly optimistic view of sun safety. In other words, individuals have miscalculated the costs and benefits of their time in the sun, believing that they are safer than they are and, thus, spending more time in the sun than before. Weinstein (1988) highlights this type of relationship, noting that the level of perceived risk is elemental in the decision to engage in precautionary behaviors. Additionally, individuals may perceive that the costs of melanoma are lower than they are, given the lack of focus and education about the costs of spending too much time in the sun and using inadequate protection measures.

A further explanation for these results derives from the literature on bureaucracy. The incentive structure for bureaucrats running the agencies responsible for researching and educating the public on the prevention of cancer is such that there is a disincentive to (1) find a cure and (2) run a successful prevention campaign. If these agencies actually achieved both of these goals, the agency would either cease to exist or, at the very least, shrink drastically in size. By emphasizing their ever-important role in dampening the increasing incidence rate of melanoma, the agencies implicated in this funding not only increase their prestige, but also increase their size and budget, thus ensuring their own job security over the long-term. The theoretical explanations underlying these resultssecondary effects and bureaucracy effects-will be discussed further in sections 2.3-1 and $2.3-2 .{ }^{9}$

\footnotetext{
${ }^{9}$ Appendix Figure 2.2 provides a chart of the secondary effects argument and two cases of bureaucracy effects.
} 


\section{3-1 The Laffer Curve and Secondary Effects}

The Laffer curve relationship has been applied to a variety of different variables, including Consumer Product Safety Commissions regulations of product safety (Viscusi 1985), enrollment and curriculum (Shmanske 2002), the Endangered Species Act (Stroup 1998), criminal sentencing and prison space (Clark and Lee 1996), union-friendly

legislation and union density (Baird 1998), public sector employment and aggregate output (Koskela and Virén 2000), auditing and net tax revenues (Sanyal, Gang, and Goswami 2000), and aid and its corresponding benefits (Lensink and White 1999).

Clark and Lee (1997) also apply the Laffer Curve relationship to the issue of mountain climbing rescues and deaths. Laws requiring the government to attempt to rescue stranded mountain climbers lowered the probability of death associated with mountain climbing. As a result, the number of climbers increased so much that the total number of deaths actually increased in spite of the lower probability of death. In other words, the behavioral response more than offset the intended outcome of the law. When an activity is made safer, the risk price is reduced, thus causing secondary effects. Peltzman (1975) applied this logic to the effects of automobile safety regulation, finding that an increase in safety regulations and the corresponding reduction in the probability of death gave rise to more risk-taking by drivers. Peterson, Hoffer, and Millner (1995) use the same logic for their study of air-bag-equipped cars, finding that there is a secondary effect in the form of more aggressive driving. The work of Blomquist (1988), Chirinko and Harper (1993), Keeler (1994), and Sobel and Nesbit (2007) also offer corroborating evidence of secondary effects when the safety of automobiles is increased. 
If the secondary effects logic is applied to skin cancer, one would expect to see more risk-taking (i.e. increased use of tanning beds and overexposure to the sun) with increases in prevention spending and products. Research breakthroughs and greater knowledge of risk and prevention factors reduce the risk of developing skin cancer from sun exposure; however, a decreased probability of skin cancer increases risk-taking behavior. Put another way, this is consistent with the upper portion of the Laffer Curve (see Laffer 2004). Attempts to lower the risk and harmful consequences of skin cancer have been threefold: (1) improvements in sun protection technology and increased knowledge of biological and environmental risk factors, (2) improvements in medical technology related to skin cancer detection and treatment, and (3) increased efforts in education and prevention.

Each of these three attempts fall under the larger umbrella of research, prevention, and treatment functions of government-sponsored cancer institutes and can be examined through the lens of secondary effects, thus offering insight into why the melanoma incidence rate has been steadily rising even with these efforts. As mentioned before, improvements such as stronger and longer-lasting sunblock, sun protective clothing, and broader knowledge of risk factors have the secondary effect of making individuals feel safer in the sun. Thus, individuals may underestimate the costs of increased sun exposure time. Second, improvements in detection and treatment also reduce the expected costs of overexposure. When the consequences of overexposure to the sun are thought to be easily ameliorated with treatment, the expected cost of risky sun behavior decreases. In other words, sunburns aren't as costly as previously expected due to improvements in treatment. For example, surgical excision of the melanoma generally results in smaller 
scars due to surgical advances, there are cosmetics created to disguise the scars of excision, and there have been numerous advances in the variety of treatment options available. When these new treatment options are widely acknowledged in the media, the information costs associated with learning about the improved techniques drops significantly. As a result, the rapid spread of new treatment knowledge can lead to widespread decreases in individuals' estimation of the cost of risky sun exposure. As explained earlier, this provides an incentive for increasing the amount of risky behavior individuals engage in, possibly leading to an even larger incidence rate. ${ }^{10}$

Finally, the educational focus of government agencies - the focus of the empirical analysis offered earlier - has largely been on skin cancer prevention and the sun safety options available. In December of 1971, President Nixon announced the "War on Cancer," granting greater power and budgets to the National Cancer Institute. While focusing on the positive aspects of sun protection and neglecting the very real and serious consequences of skin cancer, prevention campaigns may cause individuals to underestimate the costs of overexposure, believing that their risk is now lower than it truly is and that the consequences of more risky behavior are relatively minor. For example, Dr. Richard Adamson, former director of NCI's Division of Cancer Epidemiology, "trivialize[d] the risks of food contaminated with pesticides shown to be carcinogenic in validated rodent tests" (Epstein 2003: 9). In other words, Epstein asserts that the public was ill-informed by NCI of the risk of cancer from consuming food treated with pesticides. This leads to a large-scale problem of underestimated potential costs of

\footnotetext{
${ }^{10}$ While this should not be interpreted as suggesting that new treatments be stifled or unpublicized, the analysis offered here reflects on the unintended consequences associated with well-known treatment breakthroughs and provides another potential contributing factor in the skin cancer paradox.
} 
the behavior, resulting in more of the behavior than would have been optimal had the relevant risks been accurately conveyed to the public and appropriately weighted in their behavioral decisions. This type of misinformation further exaggerates the miscalculation of skin cancer risks, resulting in more risky behavior that can lead to higher incidence rates. As indicated previously, even education about treatment breakthroughs can have undesirable and unintended consequences.

The secondary effects of government-sponsored research and prevention education campaigns can be further explained when the costs and benefits of overexposure are considered. Calder and Aitken (2008) provide evidence that young adults do not understand the long-term consequences of overexposure. Due to this fact, young adults understate the long-term costs of overexposure, making risky sun exposure more appealing. This miscalculation of risk is supported by the work of Jones et al. (2000), Murray and Turner (2004), and Health Education Authority (1997). Given that there is a tendency to underestimate the harmful effects of overexposure and skin cancer, these costs are considered to be relatively small compared to the benefits of having a tanned appearance (Baker 2002). The Health Education Authority (1997), Gerbert et al. (1996), and Lamanna (2004) all find evidence that the consequences of skin cancer are undercalculated; thus, the perceived cost is lower than the actual cost. In other words, there is more risk-taking than there would be if costs were correctly perceived. Though prevention education would be expected to decrease the incidence rate of cancer, the resulting overvaluation of safety and undervaluation of long-term costs results in a higher incidence rate due to more risky behavior. Viscusi's (1985) research on the safety effects of product safety regulation highlights this behavioral result, noting that consumers 
overstate the safety benefits of regulation, thus engaging in more risky behavior and offsetting the goals of regulation.

Some negative effects of sun overexposure can be corrected, thus further decreasing the costs of overexposure. For example, photoaging refers to the visible effects on the skin of overexposure to the sun. Since there are corrective treatments for this visible effect of overexposure, the cost of overexposure is lowered, resulting in more careless sun safety, including the use of tanning beds (Donley-Hayes 2008).

In sum, all of these efforts can be undermined by the increase of risky behavior due to improvements in sun safety, melanoma treatment, and prevention education. This theory is supported by an increase in cases of melanoma in spite of advances in sun protection technologies (Alexander 2008). Thus, it is critical to consider the unintended consequences that can result from well-intentioned efforts, as these secondary effects can potentially overwhelm the intended policy outcome, worsening instead of improving the incidence rate. The next section examines the second theoretical explanation for the skin cancer paradox - the skewed incentives created by bureaucracy.

\section{3-2 The Bureaucracy of Cancer}

Economic theories of bureaucracy are a crucial element necessary in understanding the ineffectiveness of cancer prevention and research programs run by government agencies. The core of the economics of bureaucracy is the assumption that bureaucrats, like any economic agent, act in their own self-interest. In other words, bureaucrats do what is in their best interest given the incentives created by the bureaucratic structure of these organizations. Thus, the incentives created by the organization are paramount in 
determining outcomes. If in an electable position, this translates into vote-seeking behavior. When applied to bureaucrats running government agencies, this translates into the desire for larger budgets, which result in greater fame, power, prestige, and a larger agency (see Niskanen 1971). Niskanen (1968: 293-294) posits that each of the potential variables related to a bureaucrat's utility—"salary, perquisites of the office, public reputation, power, patronage, ease of managing the bureau, and ease of making changes"-are positively related to the size of the agency's budget; thus, bureaucrats seek to maximize their utility by maximizing the budget of their agency.

When this logic is applied to agencies responsible for the prevention and research of cancer, one should not expect to see particularly effectual efforts in these areas of responsibility. This is not to say that these bureaucrats are malevolent or would not like to find a cure or better treatments for cancer. On the contrary, they are responding to the incentives they face given the structure of the organization. Despite the best of intentions, perverse incentives lead to perverse outcomes. To garner greater budgets, agencies have a strong incentive to overstate their achievements and emphasize that, given more money, a solution (i.e. cure) can be found in the near future.

In the most extreme cases, this can lead to outright fraud, as was the case with the National Surgical Adjuvant and Bowel Project (NSABP) of NCI. Newspapers uncovered the story of fraudulent data reported in the NCI study that led to the contamination of repeated breast cancer studies. NCI neglected to inform the public that the drug tamoxifen, given in a breast cancer prevention study, can cause uterine cancer and, subsequently, result in death (Schwartz 1994). In the face of an incentive structure that encourages budget maximizing behavior, this type of undesirable outcome is a 
possibility; with more studies comes more funding. A red flag raised in one study puts a hold, either temporarily or permanently, on repeated studies of the same nature.

In yet another case, Dr. Marc Straus was charged in 1978 of submitting false data in an NCI study conducted at Boston University (Schmaus 1981). Senator Orrin G. Hatch later accused the NCI of mismanagement, as Straus had been given another 1.3 million dollar research grant from NCI after his fraud was revealed. In 1978, NCI encountered another scandal when it was found that cells used in a study of Hodgkin's disease had been contaminated with monkey cells. This may not have raised questions about the validity of NCI-funded research grants if they had investigated the study further when they were informed that the samples contained an enzyme not found in white people, from whom the samples were supposedly taken (Schmaus 1981). The fraudulent behavior in this case is an example of the potential for perverse outcomes due to bad incentives. In order to obtain a grant, a research proposal must appear legitimate. In order to continue receiving funding for future studies, both the researcher and the agency have strong incentives to report successful results and progress even if, in the extreme case, this means falsifying results or covering up flawed samples. Each of the previous examples illustrates how the ever-growing budget of the NCI has been misused, contributing to little progress in the "war on cancer."

Given the bureaucratic goal of maximizing budgets, there is often therein an incentive to befriend special interests in the hope that lobbying will further increase an agency's discretionary funds. Similar to the theory of regulatory capture, in the cancerfighting industry, special interests capture the cancer agency. Companies manufacturing the drugs to treat cancer have the lure of greater profits if cancer agencies place the bulk 
of their research efforts in discovering treatments and prevention methods that result in a new drug being created for the market. For example, if a homeopathic or behavioral method is the focus of research, drug companies have little or nothing to gain. However, if a government-funded research study devotes their time and funding to developing new chemical combinations that can be used in treatment or prevention, drug companies have much to gain. When NCI research uncovers new evidence of a successful drug treatment, this is passed on to a drug company to manufacture the product, and it is the company who will retain the patent for the new treatment.

On the other side of the coin, it is also in the interest of the cancer bureaucracy to focus on the research desired by drug company special interest groups. There are two reasons for this: 1) individual benefits resulting from future potential employment in the private sector and 2) agency benefits resulting from special interests lobbying on their behalf. There is a high incidence of former NCI leaders accepting jobs at private drug manufacturing companies after their stint at NCI, providing incentives for NCI to focus on research capable of conferring benefits to these companies. Researchers for the NCI have also been implicated in a conflict-of-interest scandal for accepting consulting money from drug companies (Willman 2005). Additionally, the agency benefits from following the same research path because special interest lobbying funded by drug companies can appeal to legislature for larger budgets for cancer-fighting agencies.

It is, therefore, unsurprising that the NCI has been accused of favoring cancer treatments that result in large profits for drug companies, such as chemotherapy and laboratory-produced drugs, and neglecting less expensive alternatives, such as research into homeopathic treatments. As the director of NCI from 1989 to 1995, Dr. Samuel 
Broder, stated, "The NCI has become what amounts to a government pharmaceutical company" (Fellers 1998). One such example of this is the NCI's study of Laetrile, in which they conclude that the inexpensive treatment "has no value and is not without toxicity" (as stated in the National Cancer Advisory Board Minutes of February 1-3, 1982: 6). It is also noted in these minutes that the validity of NCI's results was in question. Another example from the same set of minutes is the lack of emphasis on nutritional approaches to cancer treatment, as evidenced by Dr. Maureen Henderson's request for additional resources for this research and inclusion of more specialists in related fields. This request was met with "skepticism" (12). Potential research avenues that may diminish the skin cancer incidence rate are, thus, being largely neglected in favor of pharmaceutical company interests.

It is, of course, in the interest of these agencies, such as the National Cancer Institute, to highly publicize the seriousness and extent of cancer as a means of generating more funding. However, it is not in their interest to actually find a cure or be especially effective at prevention. If they are successful in those goals, their agency would greatly shrink or possibly cease to exist entirely. In the interest of keeping their jobs and receiving ever-increasing budgets, a self-interested bureaucrat would strive to be only as successful as is necessary to retain her job title but not successful enough to eliminate her job or shrink the agency's funding. Epstein and Young (2004) poignantly note, "Paradoxically, it seems that the more we spend on cancer, the more cancer we get." To overstate the agency's effectiveness and argue for more funding, bureaucrats may resort, in the extreme case, to reporting the figures in a way that makes their efforts look more successful than they actually were. One such case, whether intentional or not, 
was the NCI's Surveillance, Epidemiology, and End Results (SEER) program. SEER was created as a cancer database, providing estimates of, among other things, the incidence rates of different types of cancer. When the initial survey was conducted, it was found that the program had taken samples that misrepresented the U.S. population, including too few blacks and Hispanics, which likely biased the estimates downwards, indicating a lower incidence rate than exists (Boyd, ed.1982). Both blacks and Hispanics have a higher mortality rate from melanoma and tend to receive diagnosis at a more progressed stage in the disease.

Yet another issue of relevance is the difficulty of measuring efficiency in the public sector and the incentives created as a result. As Mises (1944) theorized, the government bureaucracy has no measure of its success equivalent to that of the private sector, thus making it impossible to determine the optimal allocation of resources in this sector. The core of the problem arises from the lack of a profit motive in the public sector and the unfortunate reality that the utility of a bureaucrat is positively correlated with the budget of the agency. Accordingly, the minutes from the National Cancer Advisory Board's (May 18-20, 1981) meeting indicate that Government Accounting Office (GAO) audits of NCI identified "deficiencies" in their management of contracts (6). As Mises (1944: 48) explains, the common citizen, evaluating a bureaucracy from the private sector point of view, "discovers that bureaucratic management is wasteful, inefficient, slow, and rolled up in red tape." Without the feedback of profits or losses, it is difficult to measure efficiency and success.

Tullock's (1965) work on bureaucracy explains the incentive side of the inefficiency argument, noting that there is less incentive for improving efficiency in the 
public sector as compared to the private sector because of the inherent problems in measuring public sector efficiency. Without the typical revenue-expenditure relationship and market price for output present in private firms, bureaucratic agencies cannot be expected to achieve the most efficient outcomes. Hence, it is unsurprising that the trend we observe is a rapidly increasing budget and an increase in the melanoma incidence rate.

The theory of bureaucracy, when applied to the cancer industry, illuminates the effect of the structure of cancer-fighting agencies on the outcomes they produce. To reiterate, it is the bureaucratic incentives that produce bad outcomes, not the malevolence of an individual working for the agency. In other words, when stories of fraudulent reports or mismanaged funds are revealed, whether the individual(s) responsible are benevolent or malevolent is not the question of greatest importance; instead, it is critical to question the incentives that would encourage such behavior. Constructing the incentive structure of the cancer industry in a way that provides incentives for progress and disincentives for fraud and waste is a key element in fostering an environment that promotes success.

\subsection{Conclusion}

This analysis explains the skin cancer paradox, which resembles the backward-bending portion of the Laffer Curve. The insights offered by economic analysis provide serious implications for public policy pertaining to skin cancer prevention and research. There are three key insights to be taken from this analysis. First, the relationship between National Cancer Institute spending and the incidence rate of melanoma for the 1975-2004 
period displays a positive relationship, indicating that increased spending and its consequential reduction in the probability of death from melanoma is associated with an increase in the melanoma incidence rate consistent with the backward-bending portion of the Laffer curve (see Figure 2.1). Second, the secondary effects of prevention spending and the resulting perceived costs and benefits of sun safety are elemental in this relationship. Third, the incentives faced by bureaucracies are such that a policy of ineffective but ever-increasing spending leads to these perverse outcomes.

A public policy with heavy emphasis on sun safety and preventative measures, in addition to the broad range of sun protective items, has not been effective in reducing the incidence rate of melanoma. The same is true for publicized treatment advances and exaggerated claims of success. The secondary effects associated with an emphasis on safety and exaggerated reports of success in the "war on cancer" can result in an undercalculation of the true costs of sun exposure and lead to more risky behavior.

To allocate prevention education resources in a more productive manner, there must be a shift in focus to the dangerous outcomes of skin cancer. Education about the dangers of melanoma and the subsequent possibility of death would increase an individual's cost calculation of overexposure to the sun, thus reducing the amount of risky sun behavior. In spite of the government's stated goal of reducing skin cancer rates through research and prevention, it appears that their attempts have been misguided at best and harmful at worst. For example, some survey results indicate that consumers are unaware of what SPF sunscreen should be utilized and how often it should be reapplied 
given the activity one is engaged in. ${ }^{11}$ As in the aforementioned cases of government safety regulations for automobiles and many other products, an effort to increase public safety could actually provoke more individuals to engage in risky behavior, thus resulting in a larger number of the negative outcome the policy was intended to prevent. In order to avoid this outcome, the focus must be on how unsafe sun overexposure is rather than the safety sunscreen provides. This "reverse psychology" type of policy may reduce the amount of risky behavior individuals engage in by convincing them that they are not as safe as they previously believed.

Consideration should also be given to the perverse incentives currently at play in the bureaucratic agencies involved in skin cancer research and prevention. In their current form, these bureaucracies provide incentives encouraging budget maximization. Given the incentives faced by bureaucrats in these agencies, it should come as no surprise that mismanagement of funds and fraudulent or exaggerated research results have been observed. Additionally, the capture of cancer bureaucracies by drug company special interests leads to incentives promoting research into costly new drug treatments and a lack of extensive exploration of alternative, and often less expensive, treatment avenues. The lack of feedback mechanisms to measure the efficiency of cancer bureaucracies results in a lack of incentives to pursue skin cancer research and prevention in an efficient manner. Elimination of the misguided policies currently being used is essential for a turnaround in the incidence of melanoma.

\footnotetext{
${ }^{11}$ http://info.cancerresearchuk.org/images/pdfs/sunsmartonssurvey.
} 


\section{CHAPTER 3}

\section{A Rational Ritual: The Economics of Female Genital Mutilation}

"Every year, three million girls and women are subjected to genital mutilation/cutting, a dangerous and potentially life-threatening procedure that causes unspeakable pain and suffering." (UNICEF 2005a: vii)

\subsection{Introduction}

Female genital mutilation (hereafter FGM) involves the partial or complete excision of external female genitalia (primarily the clitoris and labia majora and minora) and other damage to the female genital organs. ${ }^{12}$ The practice of FGM is one of the most significant health and human rights issues in the world today (UNICEF 2005a, World Health Organization 2008). FGM is typically classified into four categories:

(1) clitoridectomy - partial or complete removal of the clitoris and/or prepuce,

(2) excision-partial or complete removal of both the clitoris and the labia minora, sometimes including removal of the labia majora,

(3) infibulation - decreasing the size of the vaginal opening by cutting the labia minora and/or the labia majora and resealing the cut regions to create a seal over a portion of the vaginal opening, sometimes including removal of the clitoris, and

(4) all other injury to female genitals not justifiable for medical reasons, such as pricking, piercing, scraping, etc. (World Health Organization 2008: 4).

\footnotetext{
${ }^{12}$ We use 'female genital mutilation' in the broadest sense to include female genital cutting and female circumcision.
} 
Most (i.e., 90\%) cases of FGM are Type 1, 2, or 4; only $10 \%$ are Type 3 (Yoder and Kahn 2007).

FGM's global prevalence is significant, with an estimated 130 million living women who have undergone the procedure (UNICEF 2005a: 1). The practice is found most often in Africa (especially the western, eastern, and north-eastern regions) as well as in some countries in Asia and the Middle East. The practice of FGM also takes place among some immigrant populations in Europe and North America. Among countries where FGM is practiced, the rate of prevalence varies widely from less than $1 \%$ to near $100 \%$. The age at which FGM is performed also varies but is generally conducted on young females between age 0 and 15, though some adult females also undergo the practice (World Health Organization 2008: 4). FGM is performed, on average, on girls who are 7 years old (Merck 2005).

A considerable portion of the existing literature on FGM employs anthropological analysis (see Gruenbaum 2001), including a large number of detailed studies based on fieldwork and interviews (see, for example, Abdalla 1982; Lightfoot-Klein 1989a, 1989b; Isa, Shuib and Othman 1999; Yount 2004; Hernlund and Shell-Duncan 2007). Existing research also reviews and analyzes initiatives and efforts to change or end the practice of FGM (see Dorkenoo 1994). Kalev (2004) focuses on FGM from the standpoint of women's rights and human rights more broadly, while DeJong (2006) focuses on general issues of reproductive health, including FGM, for the well-being of women in developing countries. Finally, international development, health and human rights organizations have written studies on the practice of FGM, emphasizing its risks as well as specific 
policy implications for generating change (see UNICEF 2005a, 2005b; World Health Organization 2008).

Largely absent from the existing literature is the application of rational choice analysis to the practice of FGM. There are exceptions. Mackie (1996) provides a 'convention account' for the existence of and parallels between the practices of infibulation and footbinding. Chesnokova and Vaithianathan (2007) provide an empirical analysis of female genital cutting and marriage in Burkina Faso. They find that female genital cutting is correlated with better marriage outcomes in terms of women marrying earlier, living in wealthier households, and being the first wife in polygamous households. While both of these studies rely on rational choice theory to understand FGM, neither provides a complete analysis of the persistence and evolution of the practice.

This paper fills the existing gap in the literature by developing the "economics of female genital mutilation.' Specifically, it provides a rational choice analysis of the practice of FGM and, in doing so, answers the following questions: (1) why does the practice of FGM persist? and (2) why and how does the practice of FGM change? Finding answers to these questions is important for at least two reasons.

First, FGM poses significant health risks including pain, bleeding, shock, urinary problems including retention and infections, pelvic infections, infertility, menstrual problems, and sexual difficulties (Obermeyer and Reynolds 1999; Gruenbaum 2001: 47). There are also significant health issues associated with child birth, including an 
increase in the number of caesarean sections, post-partum hemorrhaging, and the increased probability of infant death (World Health Organization 2008).

Second, FGM is considered to be a major human rights issue as it deals with questions of women's and children's rights and matters of bodily integrity. According to a recent UNICEF report, the practice of FGM “...violates girls' and women's basic rights, denying them of their physical and mental integrity, their right to freedom from violence and discrimination, and in the most extreme case, of their life" (2005a: vii). A central element of this debate is the issue of cultural rights versus human rights (see Kalev 2004).

Given the health and human rights issues surrounding FGM, having a complete understanding of the various aspects of the practice is of utmost importance. It is our contention that a rational choice analysis of FGM can make an important contribution to our understanding of the ritual. Our analysis avoids normative (i.e., ethical) judgments regarding FGM and instead focuses on the positive (i.e., empirical) aspects of the issue. The goal is to provide insight into why, once adopted, FGM persists over time and how it can change. In doing so, we explore the rational foundations for a ritual, which is often viewed as something “...inherited from an untraceable path which has no rational meaning and lies within the realm of untouchable sensitivity of traditional people" (Toubia 1993: 4). In contrast to the view that FGM is an irrational practice, our central argument is that FGM is, indeed, a rational ritual.

This analysis contributes to several strands of literature, the first of which is the existing literature on FGM discussed above. Second, we contribute to the economic 
development literature grounded in the 'capabilities approach' proposed by Sen (1992, 1993, 1999). In contrast to standard metrics of development- per capita income, etc.this approach focuses on the well-being of individuals in terms of their capabilities to function and pursue the courses of actions which allow them to live a worthy and dignified life. Nussbaum (2000) extends the capabilities approach to women in developing countries and emphasizes the importance of bodily health and integrity, among other capabilities. Our analysis contributes to this literature by clarifying why practices which potentially undermine capabilities emerge and persist over time. Finally, our analysis contributes to existing work in the area of new institutional economics (see Williamson 2000). Research in this area focuses on formal and informal institutions as the 'rules of the game' and analyzes how these rules emerge, persist and change over time. FGM is an informal institution which is deeply embedded in the cultural fabric of societies where it is practiced.

We proceed as follows. Section 3.2 provides background regarding the history of FGM, including common explanations for the existence of the practice as well as stylized facts. The next two sections develop the economics of FGM. Section 3.3 explains why FGM tends to persist due to institutional path dependence and its connection to group identity. Section 3.4 explores the mechanisms contributing to changes in FGM practices. Finally, Section 3.5 concludes with the implications of the analysis.

\subsection{FGM—Background and Stylized Facts}

Given its antiquity, identifying the specific origins of FGM is difficult. Some have traced the practice back to the ancient civilizations of Egypt and Sudan in the Nile Valley (see 
Assaad 1980; Sanderson 1981). Others link its origin to the pharaohs and the belief that male and female circumcision was needed to unambiguously establish one's sexuality (Skaine 2005; Gruenbaum 2001: 43). Still others emphasize the link between FGM and slavery. Beachey (1976) notes the role of FGM in the Egyptian trade of black slaves from the Dynastic to the Byzantine period and the importance of the practice for the trade of Sudanic slaves to the Persian Gulf prior to the rise of Islam. In both cases slaves were subjected to FGM as a means of preventing pregnancy and sexual promiscuity.

While the exact origin of the practice is an unsettled issue, there are four common explanations for the existence of FGM in the literature on the topic. First, in many societies the practice of FGM is viewed as a 'coming-of-age ritual.' From this standpoint, the ritual of FGM is viewed as a significant part of the transition from childhood to adulthood (see Yoder et al. 1999; Ahmadu 2000). Second, FGM is often viewed as being necessary for marriage because it ensures a women's virginity by discouraging what is deemed to be immoral sexual behaviors (see Abdallah 1982: 52-3; Ahmadu 2000; Gruenbaum 2006). The practice discourages this behavior by reducing the pleasure associated with sexual intercourse. ${ }^{13}$ A related justification is that FGM is a means of ensuring the cleanliness of a woman, thereby increasing her marriage prospects (see Talle 1993; Ahmadu 2000; Johansen 2007). Third, FGM is often linked with religious practices and obligations (see Lightfoot-Klein 1989; Gruenbaum 2006; Johansen 2007). The practice can be found among Catholics, Jews, Protestants, and Muslims, among others (Dorkenoo 1994: 36). A fourth explanation for the existence of

\footnotetext{
13 As Gruenbaum (2001: 156) notes "if sex becomes painful or is associated with psychological trauma, that is likely to decrease orgasmic ability."
} 
FGM is patriarchy. From this perspective, the origins of FGM can be found in social power structures, specifically the dominant role of males over females (Gruenbaum 2001: 39-42; World Health Organization 2008: 6).

While there is some support for each of these explanations, each reason, by itself, fails to provide a complete explanation for the existence of FGM across societies with different cultures and characteristics. For example, the religious explanation fails to appreciate that the origins of FGM predate Islam and Christianity. Further, the empirical relationship between religions and the prevalence of FGM is inconsistent across countries (UNICEF 2005b: 10-11). Likewise, the patriarchy explanation fails to explain why FGM is not universal across all patriarchal societies.

Although there is no single explanation for the existence of FGM, we identify two stylized facts regarding the practice:

(1) Where it exists, the practice of FGM tends to persist for long periods of time. Once established, the ritual of FGM often sustains for significant periods of time. Consider, for instance, the cases of Egypt and Ethiopia. The practice of FGM in these countries has been traced back to 500 B.C. (Gruenbaum 2001: 43). In both countries the practice continues to this day and both Egypt (97 percent) and Ethiopia (90 percent) are among the countries with the highest prevalence of FGM (Gruenbaum 2001: 8).

(2) Even where the FGM ritual has persisted for long periods of time, relatively rapid movement away from the practice is possible. 
While FGM often persists for significant periods of time, one observes cases where the practice of FGM changes and the overall prevalence falls relatively quickly given the period of time the practice has persisted. Studies indicate that the rate of prevalence has declined in several countries, including Benin, Burkina Faso, Central African Republic, Eritrea, Kenya, Nigeria, Tanzania, and Yemen (UNICEF 2005a). In some cases FGM has been completely abolished while in others there have been decreases in levels of prevalence. As will be discussed in Section IV, Senegal is one notable case where the prevalence of FGM has decreased in a relatively short period of time.

The subsequent sections aim to explain these stylized facts. Section III explains why the practice of FGM persists while Section IV explores how the practice can change.

\subsection{Why Does FGM Persist?}

A defining characteristic of institutions is their stability and durability over time (see North 1990). This is especially the case for informal institutions which are 'embedded' within the broader social fabric. As Williamson (2000: 597) notes, embedded institutions “...display a great deal of inertia-some because they are functional (such as conventions); others take on a symbolic value...many are pervasively linked with complementary institutions (formal and informal), etc." Why does FGM tend to persist once it is adopted? To answer this question, we identify two mechanisms - institutional path dependence and the importance of group identity—which contribute to the durability of FGM over time. 
First introduced by North (1990: 93-96), the notion of 'institutional path dependence' emphasizes the increasing returns to institutions which tend to 'lock in' particular institutional arrangements that have emerged in various places for unique historical reasons. There are several explanations for institutional path dependence, including: (1) high fixed costs, (2) learning effects, (3) coordination effects, and (4) adaptive expectations.

The logic of institutional path dependence is applicable to the practice of FGM. Where it exists, the practice of FGM is an established means of signaling future behavior. As noted in the previous section, FGM may serve as a sign of purity or commitment to a religion or other cultural traditions. The set-up costs associated with establishing an alternative to replace the FGM ritual are high. This is especially the case if the alternative is created de novo. Not only must alternative signals be established, but people must learn about the alternative and be confident that others know about the new ritual and its meaning. There are also significant learning effects associated with FGM, as specific social arrangements have emerged around the opportunities created by the practice. For example, where FGM exists there are social structures including 'gatekeepers' who advise younger females regarding the ritual as well as practitionersmidwives, priests, nurses, and doctors - who perform the operation. Further, the meaning of the FGM ritual is well-known to members of the community. Coordination effects exist because FGM is often an established signal not only within communities but also across societies. Widespread coordination around the practice lowers transaction costs across communities, resulting in the subsequent reinforcement of the FGM ritual. Finally, adaptive expectations are involved because increased prevalence of the FGM 
ritual reduces uncertainty regarding the permanence of the practice in future periods. Adaptive expectations refer to the fact that people develop their future expectations based on what happened in the past. As an increasing number of people accept and participate in the FGM practice, this further strengthens the expectation that the ritual will continue in future periods. The interaction of all of these factors results in increasing returns to the institution of FGM leading to its persistence over time.

Viewing FGM through the lens of institutional path dependence not only provides insight into why the practice exists, but also offers insight into what institutional change entails. Specifically, change away from the FGM ritual involves a "collective action problem' which requires the coordination of a large number of people around a new institutional arrangement. People must be willing to adopt the alternative arrangement and must also be confident that others will do the same. In other words, change requires a solution to a coordination problem through the creation of common knowledge so that members of the relevant communities are confident in the widespread adoption of the new arrangement. Because of the increasing returns associated with the practice of FGM, the switching costs associated with movements away from the practice are often high; thus, FGM will tend to persist where it is already established.

Yet another reason why the practice of FGM tends to persist once adopted is that the ritual is closely connected to individual and group identity. In general, identity is an important influence on human behavior. Building on this realization, Akerlof and Kranton (2000) develop the 'economics of identity' to understand how identity influences economic outcomes. They conclude that many behaviors that appear irrational (e.g., 
gang violence) are actually rational from the standpoint that they perpetuate and strengthen individual and group identities.

The dynamics of identity is clearly at work in the case of FGM. Where FGM exists, females are taught from an early age that the ritual is an important part of maintaining good standing (i.e., identity) in the broader community. Further, part of people's identity as a 'good' parent is often tied to their daughter's participation in the FGM ritual. In summarizing the results of a survey on FGM, Yoder et al. (2004: 43) notes that "among the women who think FGM/C [Female Genital Mutilation/Cutting] should continue, half to two-thirds regard FGM/C as part of their commonsense understanding of what parents should do for their daughters - that they are doing what they think is appropriate." In this case, one's identity as a parent is directly linked to continuing the practice of FGM.

The economics of identity can be applied to FGM to provide insight into the practice. At the core of the Akerlof-Kranton model is the assumption that identity is grounded in social categories existing in a specific context. Where the practice of FGM exists, relevant categories may include being a good parent, being an adult versus a child (i.e., coming-of-age), being a suitable marriage partner, or being a member of a religious organization or a certain peer group. An important aspect of utility comes from identity, which is a function of an individual's social category, as well as the extent to which there is a match between an individual's characteristics and the prescription (i.e., acceptable behaviors) of the social category. Also important is whether the actions of others in the peer group align with the prescription of the social category. This implies that people derive satisfaction from their own behavior as well as from the emergence and 
strengthening of an identity that fulfills the prescription associated with a specific social category.

To provide a concrete example, consider the social category of 'good parent' in a society where FGM is widely accepted. In such a context, parents derive utility from ensuring that their daughters participate in the ritual of FGM on two margins. First, they increase their daughter's prospects on the marriage market. Holding all else constant, knowing that their daughters have more as compared to fewer marriage options will increase parents' utility. Second, parents also derive utility from strengthening their identity as 'good parents' in the eyes of others in the broader community who are also part of the same social category.

A key aspect of the identity model is the spillover effects of individual behavior on the broader social group. The actions of one person affect the identity of others. For example, the identity of 'good parents'-where the prescription is ensuring that daughters participate in the ritual of FGM - may be threatened by a child who resists participation.

Similar logic also explains why the practice of FGM persists even in the presence of health risks and issues of women's rights and why young females often look forward to participating in the FGM ritual despite the associated pain (Abdallah 1982: 51; Dorkenoo 1994: 46, 161). To understand why, consider the social category of 'adult' in a society where the practice of FGM is well established. The ritual of FGM is often viewed as an important coming-of-age ritual, signaling the transition from childhood to adulthood. In such cases, FGM is rewarded by the existing group of adults - consisting of those who have already participated in the FGM ritual. Females, or the parents of 
females, who resist participation in the FGM ritual threaten the identity of other members in the adult group. ${ }^{14}$ The result is that part of the prescription of being in the adult category is to punish those refusing to participate in the ritual in order to protect the identity of the group. This punishment often takes the form of ostracism or harassment of varying degrees (World Health Organization. 2008: 5). In some cases the number of marriage prospects available to females refusing to participate in the FGM ritual is significantly diminished. In other cases the family of the daughter refusing to participate is shamed by the community. At the extreme, refusal to participate in the ritual is met with physical violence and expulsion from the community.

The 'identity game' developed by Akerlof and Kranton is shown in Figure 3.1 and clarifies the dynamics of identity described above. It also illuminates the conditions under which practices linked with identity persist or change.

\footnotetext{
${ }^{14}$ One important issue with the application of rational choice analysis to FGM is the fact that children are the central participant. As noted in Section I, the age at which FGM is performed varies, but the practice is performed, on average, on girls who are 7 years old. There is evidence that this average age lies within the range at which children are capable of engaging in some form of rational decision making. For example, Jean Piaget's well known 'stages of intellectual development' indicates that children in the 4-7 range are able to grasp basic logical concepts, while children in the 7-11 range are able to engage in logical and organized thought. Initial evidence from experimental economics appears to confirm Piaget's hierarchy. For example, Harbaugh et al. (2001) find that seven-year-old children show clear evidence of basic rationality. The ability to rationalize is demonstrated by cases of young girls leaving their homes and families to avoid having to participate in the FGM ritual as well as instances of parents refusing to subject their daughters to FGM (see Gruenbaum 2001: 216-7). This indicates that many young females, as well as parents, are able to weigh the costs and benefits associated with FGM. In general, either the young female or her parents will be the relevant chooser when it comes to making decisions regarding FGM. Either way, the costs and benefits associated with the practice of FGM will influence the ultimate decision made regarding participation. For example, even in cases where the parent is the relevant decision-maker, the externalities of FGM on the parent-seeing their child in pain or experiencing other side effects associated with the procedure and their status as "good parents" in the community - will ultimately impact their costs and benefits and, ultimately, their decision.
} 


\section{Figure 3.1: The Identity Game}

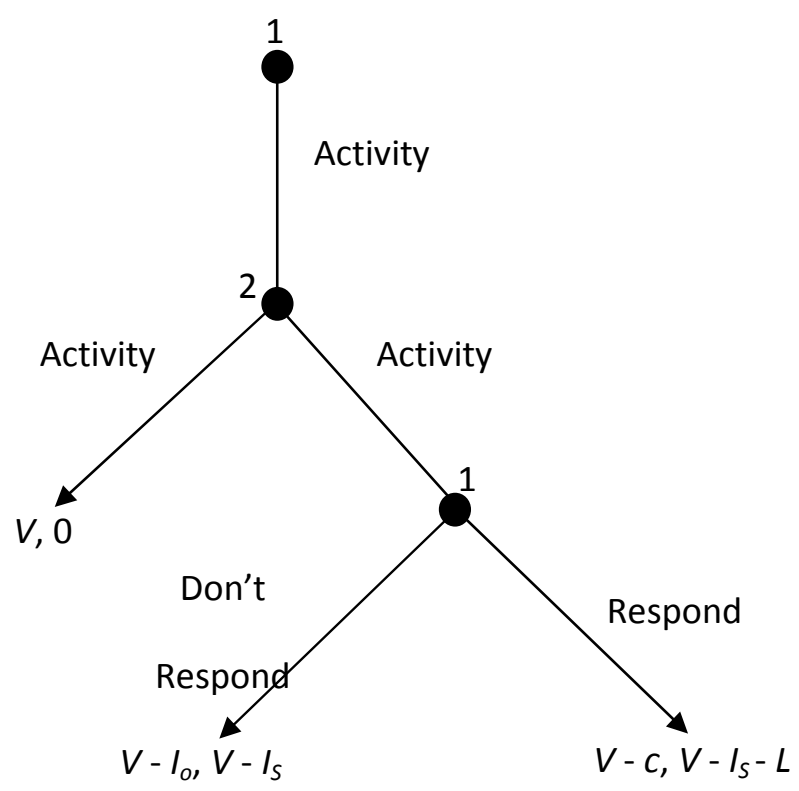

There are two players and two 'Activities'-Activity 1 and Activity 2. In the context of our analysis, Activity 1 should be understood as participation in the FGM ritual, while Activity 2 is refraining from participation. A player receives a payoff of $V$ when she chooses her preferred activity and a payoff of 0 otherwise. For simplicity, Akerlof and Kranton posit two social categories-Red and Green. They assume that all people are thought of as 'Green.' Further, they assume that the behavioral prescription for a Green is Activity 1 while the prescription for a Red is Activity 2. If a player chooses Activity 2, they are not considered to be a 'proper' Green. The result will be a loss of the player's Green identity and hence a reduction in utility by $I_{s}$, where " $s$ " refers to "self." This coincides with the case where a female or her parents refuse(s) to participate in the FGM ritual and is therefore punished through harassment or ostracism. 
In order to capture the spillovers effects on identity, the model assumes that a player who chooses an activity that runs counter to the prescribed social category also negatively impacts the other player through a loss of identity. Recall that the refusal of a female or her parents to participate in the FGM ritual threatens the identity of the broader 'adult' social category. This loss to other player is represented by $I_{o}$, where " $o$ " refers to "other."

As illustrated in Figure 3.1, Player 1 (i.e., the 'adult,' which refers to any member of the existing adult social category) chooses first. In a subgame perfect equilibrium, Player 1, as a true Green, would always choose Activity 1, hence the absence of Activity 2 as an initial option. However, Player 2 (i.e., the young female or the parents of the young female) may choose Activity 1 or Activity 2 depending on the respective payoffs. Player 2, although perceived as a Green, actually prefers Activity 2. An example would be a case where the community perceives that a young female is going to participate in the FGM ritual, but the young female or her parents do(es) not actually want to take part and resists.

Following the selection of Activity 2 by Player 2, Player 1 has two options. The first involves "responding" to Player 2's selection of Activity 2. The potential benefit of "responding" is that Player 1 restores their identity at a cost of $c$ while imposing a loss on Player 2 equal to $L$. In the context of our analysis, this would correspond to a member of the 'adult' group punishing a female who is resisting participation in the FGM ritual. The punishment imposes a cost on the reluctant female while strengthening the punisher's identity as a 'true' adult. If Player 1 chooses "Don't Respond," they suffer a loss of $I_{o}$ while Player 2 suffers a loss of $I_{s}$. 
There are four possible Nash equilibria to the game depending on the values of the relevant variables (Akerlof and Kranton 2000: 730). We interpret these equilibria in the context of our analysis to shed light on the dynamics of identity as they relate to FGM. The Nash equilibria are:

(1) Player 1 plays "Respond" and deters Player 2 from resisting the ritual of FGM when $c<I_{o}$ and $I_{s}<V<I_{s}+L$. This will be the equilibrium outcome when the loss of identity to Player 1 from Player 2 undermining the practice of FGM is relatively high and when the loss of identity to Player 2, as well as the punishment imposed by Player 1, is relatively high. This equilibrium describes those situations where FGM persists because of fear of severe responses such as significant losses of family honor, violent harassment, and extreme forms of ostracism.

(2) Player 1 chooses to "Respond" against Player 2's decision to engage in Activity 2, but this response fails to deter Player 2 from effectively resisting participation of the FGM ritual, when $c<I_{o}$ and $I_{s}+L<V$. This equilibrium indicates that movement away from the FGM ritual is possible, but high cost. The shift away from the ritual will occur only when Player 2's utility from refraining from participating in the FGM ritual is relatively high when compared to the associated cost.

(3) Player 2 chooses Activity 2 (i.e., refraining from participation in the FGM ritual) and Player 1 does not respond, when $c>I_{o}$ and $I_{s}<V$. This equilibrium represents a situation where the movement away from the FGM ritual is most likely. It is important to note though that this outcome still has a positive cost whenever $I_{s}>0$.

(4) Player 2 chooses Activity 1 no matter how Player 1 may respond if Activity 2 were chosen instead, when $I_{s}>V$. Under this scenario, refusing to participate in the FGM ritual leads to a significant reduction in utility for Player 2 due to the loss of identity. In this case the potential response from Player 1 does not even factor into Player 2's decision. Under this scenario, the practice of FGM will continue, since it is deeply intertwined with the identity of community members. 
The identity game captures many important aspects of the practice of FGM. First, where it exists, the FGM ritual is an important aspect of the identity of community members. Although we framed the identity game in terms of FGM as a coming-of-age ritual, the same logic can be applied to cases where the ritual is associated with purity, commitment to a religion, or other social categories. Second, the game illuminates the conditions under which FGM persists and those conditions under which it can change. As noted in Section II, a review of the evidence indicates that where FGM exists, it can persist and even increase in prevalence over time. For example, Côte d'Ivoire, Egypt, Guinea, Mali, Mauritania, Niger, and Sudan have not seen a significant change in the rates of FGM over time. In fact, Egypt, Mali, Guinea, and Sudan continue to have the highest prevalence of FGM (UNICEF 2005a). These cases would correspond to equilibria (1) and (4).

At the same time, we also observe cases where the practice of FGM has changed over time. For example, surveys indicate that the rate of prevalence has declined in several countries, including Benin, Burkina Faso, Central African Republic, Eritrea, Kenya, Nigeria, Tanzania, and Yemen (UNICEF 2005a). Some regions have experienced complete abolition of FGM, whereas others have experienced only marginal changes in the prevalence or methods of FGM. These outcomes would correspond to equilibria (2) and (3).

Identity plays a significant role in the persistence of FGM. When deciding whether to subject their daughter to the practice of FGM, parents will consider the social context — community expectations, social norms regarding marriage and religion, etc.and the impact of alternative choices on their identity and the identity of their daughter. Likewise, when considering whether to participate in the FGM ritual, young females will 
consider the wishes of their family as well as community expectations. Based on the perceived effect on their respective identities, the parents and daughter may rationally decide to participate in the ritual.

Once this identity decision is made and a young female becomes part of the 'adult' group, her optimal behavior is then determined by fulfilling the prescription of the 'adult' category. This explains why “...older women who have themselves been mutilated often become gatekeepers of the practice, seeing it as essential to the identity of women and girls" (World Health Organization 2008: 7). The role of 'gatekeeper' involves preparing girls for the FGM ritual, carrying out the ritual, and contributing to the punishment of young females who resist participation. While this behavior may appear irrational to outsiders, a closer look reveals that, in reality, it is the rational attempt by members of a social group to protect and strengthen their identity. This does not mean that the practice of FGM cannot change but instead indicates that one must consider the costs of movements away from the ritual, including the cost of lost identity. In the next section we consider how the practice of FGM can change.

\subsection{Why and How do FGM Practices Change?}

An important characteristic of institutions is their durability over time. At the same time, there are cases of dramatic institutional change in relatively short periods of time. For example, Mackie (1996) notes how the institution of footbinding in China ended relatively quickly given the significant period of time the practice had persisted. How do we explain observed institutional changes with the fact that institutions tend to be durable and stable over time? 
Denzau and North (1994) and North (2005) place informal institutions, and especially mental models, at the core of the process of institutional change in the face of institutional path dependency. North (2005: 23) notes that "the process works as follows: the beliefs that humans hold determine the choices they make that, in turn, structure the changes in the human landscape" (2005: 23). This suggests institutional change requires shifts in individuals' beliefs and mental models. Individuals rely on incomplete mental models since they cannot know the full range of opportunities available to them (Denzau and North 1994; North 2005). As they become aware of new meanings, perceptions, and opportunities, they update their mental models. These updates, or "periods of representational redescription," are the engine of institutional change and can, under certain circumstances, result in dramatic "punctuated" changes to existing institutions, leading to new ones (Denzau and North 1994: 23).

In terms of FGM, this implies that institutional change involves an exogenous 'shock' to existing belief systems, especially as they relate to identity. Our analysis suggests that in order for changes to the practice of FGM to be permanent, there must be changes to the costs and benefits associated with a loss of identity-both for the individual and the broader social group - for choosing not to participate in the FGM ritual. As per the identity model, changes in the values of the relevant parameters will influence the outcome of the decision not to participate in FGM. For example, decreasing the loss $(L)$ imposed by other members of the community on those that choose not to participate in the FGM ritual will lead to fewer people participating in the practice. Likewise, reducing the importance of FGM for a social group's identity will lower the value attached to the $I_{o}$ and $I_{s}$ parameters, resulting in a decrease in FGM. 
In order to change these parameters, a solution to the collective action problem must be found. Initially, there must be first movers who choose not to engage in the established FGM ritual. Further, because the ritual has spillover effects both within and across communities, common knowledge around changes must be generated. In short, widespread coordination requires that each person be confident that others are committed to the change as well. The central issue becomes understanding the 'types' of exogenous shocks that are effective in affecting these conditions.

First, consider what has not worked. Efforts by national governments and international organizations to change FGM through legal provisions have proven to be largely ineffective absent deeper changes in underlying practices. Consider, for example, the case of Egypt. In 1997, Egypt's highest appeals court, the Court of Cassation, upheld a national ban on the practice of FGM. According to the law, those that failed to follow the ban were subject to criminal punishment. Despite the national law, a 2000 survey by the United States Agency for International Development (USAID) found that $97 \%$ of Egypt's population was still engaged in the practice.

In general, there are two reasons for the failure of national laws regarding FGM. First, members of social groups practicing FGM tend to view these efforts as threats to their identity. Indeed, interviews and surveys indicate that women in societies where FGM is practiced and accepted are largely critical of attempts at exogenous change by those viewed as 'outsiders' (Dorkenoo 1994). In many societies where FGM is practiced, 'outsiders' include not only foreigners, but also members of the national government and others who are not considered to be part of the local culture. In many cases, the paternalistic views of outsiders and their disdain for the practice are viewed by insiders as 
an insult to local culture and traditions. In terms of our analysis, members of the 'adult' social group view those outside the group as threatening their identity by trying to curtail the FGM ritual and therefore resist exogenous change.

Second, the enforcement costs of formal laws, absent simultaneous changes in informal institutions, are relatively high. Without changes in underlying behaviors, members of communities where FGM exists will tend to ignore formal laws, and the practice will continue. In such instances, enforcing the law would involve arresting and imprisoning entire communities. The problem is that formal laws, by themselves, do not necessarily impact the identity parameters in a manner resulting in permanent changes in FGM practices. To understand the strength of social conventions, even in the presence of formal laws to the contrary, consider the case of immigrants from FGM-practicing societies who migrate to countries where the ritual of FGM is largely absent. In some cases immigrants continue the practice even though formal laws make FGM illegal (UNICEF 2005a: 27). This indicates that changing the practice of FGM is a matter of altering fundamental beliefs and social conventions, not simply formal laws.

It should be noted that there is evidence that formal laws making FGM illegal can be effective when they support existing opposition to the practice at the local level (see UNICEF 2005a: 29; Hernlund and Shell-Duncan 2007: 47-8). In general, formal laws will have a reinforcement effect when they codify underlying practices and beliefs. Where formal rules align with informal practices, social groups will not view their identity as being threatened. However, where there is a disconnect between formal laws and informal practices, the latter will tend to persist. 
Cases of successful changes to FGM practices have typically started at the local level. A UNICEF (2005a: 23) report notes that "the most successful [initiatives of change] are participatory in nature and generally guide communities to define problems and solutions themselves." For example, the prevalence FGM has fallen in Gambia, Kenya, Tanzania, and Uganda through the local efforts of non-profits and community leaders who are knowledgeable regarding local practices, culture, and perceptions of identity. These efforts still involve an exogenous 'shock' to existing belief systems through the introduction of alternative ideas, but changes to the practice of FGM are viewed by members of the relevant social groups as being voluntarily adopted instead of imposed exogenously. This means that the threat to identity is minimized and community members are more likely to 'buy in' to the alternative.

The common characteristic across the aforementioned countries where change has been observed is that FGM is associated with coming-of-age rituals. Efforts in these countries did not aim at wholesale change in the coming-of-age ritual. Instead, they emphasized maintaining the socio-cultural aspects of the meta-ritual while changing the FGM aspect (UNICEF 2005a: 26). The result was that the identity associated with the meta-ritual remained largely intact although the FGM aspect was changed. In other words, by making marginal changes to the meta-ritual, the losses of identity- $I_{o}$ and $I_{s}-$ from doing away with the FGM aspect were minimal.

Senegal is considered to be one of the most successful cases of change in FGM practices. Between 1997 and 2004, it is estimated that 30\% of communities practicing FGM made public declarations to abandon the practice (UNICEF 2005: 24). Our analysis provides insight into why this is the case. A driving force behind the change in 
Senegal is Tostan, an international non-profit organization. Tostan specializes in nonformal education, with particular emphasis on human rights. They assume a guidance role in a largely indigenous process of change. In other words, Tostan exogenously influences existing belief systems by introducing alternatives but does so through indigenous mechanisms. For example, the Tostan program is voluntary and begins by establishing a management committee consisting of members of the local community. This is followed by an education program whereby community members-adults and children - are exposed to issues of human rights, health and hygiene, and child and women's rights through interactive exercise.

In 1997, a group of women who participated in the Tostan program in the village of Malicounda Bambara voluntarily began an initiative to end the practice of FGM by refusing to subject their daughters to the ritual. Subsequently, they made a broader public declaration calling for an end to the practice. The collective action problem associated with institutional change was partially solved through the use of the local media, which was used to generate common knowledge around the anti-FGM initiative. Media can be an effective means of producing common knowledge around institutional change given its reach and 'publicness' (see Coyne and Leeson 2009). Along similar lines, a UNICEF (2005a: 24) report notes that "extensive media coverage of these public declarations [to end FGM] helps to introduce the alternative of abandonment to communities that continue the practice." In other words, the local media can create common knowledge around institutional change both within a community and across communities by exposing others to alternative institutional arrangements. Local journalists were in attendance for the public declaration in Malicounda Bambara, which had the effect of 
making the rejection of the ritual public information, both within the village as well as in neighboring villages. In addition to the media coverage, Tostan arranged public celebrations associated with the declaration, further creating common knowledge around the call for change.

The initial declaration calling for an end to FGM in Malicounda Bambara was met with resistance by some members of the local community as well as those in surrounding communities. Given the close connection between the ritual of FGM and identity, this response was rational. Other members of the 'adult' social group felt that their identity was being threatened by the declaration calling for an end to FGM. Given this, the ultimate success of the declaration required finding a mechanism for changing the perceived loss of identity- $I_{o}$ and $I_{s}$-associated with the change.

In Senegal, local religious leaders played a central role in this regard. Religious leaders are considered focal individuals among communities and typically have the ability to influence what is deemed 'proper' social, cultural and religious behavior. In other words, religious leaders have the ability to influence perceptions of identity. Further, in addition to having influence within their own community, religious leaders often have connections across communities, allowing them to influence identity on a broader scale.

Consider, for example, the role played by Demba Diawara, a religious leader in Malicounda Bambara. An important issue in Senegal was that FGM was considered critical for marriage. Further, marriages often took place across communities, so the collective action problem associated with ending the practice of FGM went beyond the 
village of Malicounda Bambara. Diawara traveled to surrounding villages where he had an established reputation in order to explain the declaration in Malicounda Bambara and to make clear the benefits of ending FGM. In doing so, Diawara was able to influence the perception of FGM as it related to the identity of village members. Specifically, he was able to lower the perceived loss in identity from ending FGM. Due largely to Diawara's efforts, members of the intramarrying group, which included thirteen villages, entered into a public declaration to end FGM.

Hernlund and Shell-Duncan (2007: 53-4) note that established leaders with community influence have been critical to ending FGM in other cases as well. In general, finding established mechanisms of credibility which can influence the perception of loss to identity are crucial to changing the practice. Additionally, the costs of lost identity can be partially or wholly offset by utilizing mechanisms for increasing the perceived benefits of belonging to a new identity schema, such as improved sexual health and belonging to a new social group. Absent changes to the perceived costs of lost identity, attempted changes will be met with resistance and the practice of FGM will continue.

\subsection{Conclusion}

Our analysis has several implications for our understanding of the practice of FGM. First, FGM is a rational ritual. The variety of participants involved in the FGM ritualchildren (as per footnote 14), parents, practitioners, community members, etc.-weigh the costs and benefits associated with participating in the practice. Recognizing FGM as a rational ritual is critical for understanding not only why the practice exists but also how 
it changes. The view of FGM as an irrational practice “...suggests that practitioners are somehow less rational than people in 'modern' societies and justifies a heavy-handed approach that strives to teach...people who are seen as 'ignorant'" (Gruenbaum 2001: 1617). As noted, this 'heavy-handed' approach by those considered to be 'outsiders' is likely to be unsuccessful because it fails to appreciate the beliefs underlying the FGM practice.

Second, the practice of FGM persists for two reasons. For one, institutional path dependence, due to increasing returns, means that, once adopted, FGM will often be selfreinforcing over time. Further, the practice of FGM is intertwined with the identity of those involved in the ritual. The decision of people to engage, or to refrain from engaging, in the practice of FGM affects not only the identity of the decision maker, but also the broader social group. The main implication is that identity plays a central role in the persistence of the FGM ritual. Efforts to alter or curtail the practice of FGM must recognize the cost of lost identity as a crucial parameter.

Finally, even in the face of institutional path dependency, the practice of FGM can change. Initial changes require some form of exogenous 'shock' to introduce alternatives to the status quo. However, given the close link between FGM and identity, the subsequent process of change is most likely to be effective when it emerges indigenously. The process of change requires not only a solution to the collective action problem, but also changes to the costs and benefits associated with the identity that fulfills the prescription associated with relevant social groups. Decreases in the prevalence of FGM require a reduction in perceived benefits to identity from participating in the FGM ritual. 


\section{CHAPTER 4}

\section{Empirical Evidence on the Publicness of AIDS Prevention}

\subsection{Introduction}

AIDS prevention has become an important political issue in the past several decades. This is unsurprising, given the fact that the spread of the disease has now been labeled an epidemic, with an estimated 33 million people living with HIV in 2007 (data from UNAIDS). ${ }^{15}$ In light of the spread of social consciousness surrounding this issue, funding to prevent AIDS has become a worldwide project, as evidenced by the WHO starting a global AIDS program in 1987 (Arhin-Tenkorang, Dyna, \& Conceição 2003). The purpose of this paper is to determine the degree of publicness of AIDS prevention policy spending. A large part of AIDS prevention spending comes in the form of education spending. It seems reasonable that a public service announcement, poster campaign, or public speaker would all be relatively public in nature. This is especially true in the sense that many of the educational programs aimed at AIDS prevention are likely to be fairly nonrival in consumption (i.e. one person's consumption doesn't interfere with another's consumption) and nonexcludable (i.e. it is difficult to exclude individuals from consuming the good), which are the key attributes of a public good.

If AIDS prevention policy spending is a Samuelsonian public good, the costs of such programs should not be a function of the number of people covered by them. In other words, small states and large states should demand the same amount of AIDS

\footnotetext{
${ }^{15}$ Note that prevention funding is directed towards both HIV and AIDS, though it is referred to henceforth as AIDS prevention spending for simplicity.
} 
prevention education. Even the treatment of AIDS could be somewhat public in nature, as antiretroviral therapy reduces the chance that patients with AIDS will spread the disease to others.

This paper determines the publicness of AIDS prevention spending. If AIDS prevention policy spending is a Samuelson public good, then the total demand for AIDS prevention would be equal to the vertical sum of individual demand for AIDS prevention. Using the premise of the median voter as the decisive voter, the theory and empirics of this paper will attempt to determine if this is the case. In other words, this model will use the median voter model to measure the public goods characteristic of collective consumption for AIDS prevention spending. Since few goods are purely public, the publicness of AIDS prevention will be measured as a percentage. In other words, this measure will indicate what proportion of AIDS spending has purely private benefits and what portion has spillover benefits. Results of this analysis have implications for future AIDS prevention spending, as public goods tend to be underprovided. Furthermore, a measure of the spillover benefits offers insight into the positive externalities conferred with this type of spending.

To begin this task, Section 4.2 will provide a brief literature review which examines some of the relevant precursors to this work. Section 4.3 will then offer an explanation of the methodology involved in determining the publicness of AIDS prevention policy spending. Section 4.4 provides empirical results. Finally, Section 4.5 presents policy implications and conclusions. 


\subsection{Literature Review}

There is evidence in the literature to suggest that AIDS prevention is a public good. Health care, in general, has also been characterized as a merit good, since a nation's consumption confers private benefits to the nation, but the good also confers public benefits worldwide (Sandler and Arce 2002). If AIDS prevention is a public good, free riding would be a likely outcome. Dalen (2005) provides empirical support for free riding using panel data on expenditures for both population and AIDS programs in 21 countries over the 1983-2002 period. He found that small donors free ride on the efforts of large donors, contributing less that their "fair" share based on their income weight (Dalen 2005). These results lend credence to the belief that AIDS funding is more public than private in nature.

In addition to the free riding evidence, the attributes of AIDS prevention lend some support for its publicness. For example, even HIV testing can have positive externalities, given that individuals testing positive can be informed of the necessary precautions to prevent the spread of the virus and the legal repercussions they face if they fail to inform potential partners of this risk. Thus, HIV testing can help prevent additional spread of HIV and AIDS.

As Berlinger (1999) said, we are in a microbial-unified world. This implies that there are benefits to preventing and treating AIDS in other areas, as this prevention lowers the donor's risk of contracting AIDS as well. Though there are no existing empirical studies of this issue, AIDS funding has been labeled as a global public good because of the global positive externalities associated with its prevention (ArhinTenkorang, Dyna and Pedro Conceição 2003). In other words, preventing one person 
from contracting AIDS confers positive externalities worldwide because that one person will not be part of the spread of AIDS. In fact, the education component of AIDS prevention could be spread from the initially educated group to others through word-ofmouth, creating further positive externalities and controlling the spread of the disease.

Leibowitz (2004) notes that education's role in improving the efficiency of providing health will be better understood with advances in information technology. Even antiretroviral therapy is likely somewhat public in nature and helps the prevention cause. "Reduced viral loads have been achieved in patients receiving antiretroviral treatment, lowering the probability of sexual transmission" (Arhin-Tenkorang and Conceição 2003: 493). Due to this effect, both funding for education and funding for treatment can confer positive externalities, thus both will be considered in the empirical analysis.

In addition to the literature related to the publicness of AIDS prevention, it is useful to examine the more general literature regarding the role of government intervention since this issue is relevant in terms of policy implications. As noted before, government provision of goods is often supported by the argument that government intervention is appropriate when the private market cannot efficiently supply a particular good (Sobel 2004). This is often the case with public goods, although there are cases in which savvy entrepreneurs have been able to circumvent the free rider problem associated with public goods. If AIDS prevention spending is, indeed, a public good, it seems there is a reasonable argument for the government to provide the good, as the good would likely be undersupplied in the private market due to non-rivalry and nonexcludability (Samuelson 1954). 
If, however, AIDS prevention spending is mostly a private good, it is likely to be more efficiently provided by the private market. There are clear policy implications in this case. In seeking efficiency, it has oft been noted that the private market, in general, does a much better job than the government, with the exception of select special cases, public goods being one of these special cases. It is important to note, however, that even in these cases that justify government intervention, the government might still perform worse than the private market (Sobel 2004). Buchanan (1962) provides further support for this assertion, discussing the political context within which government decisions are made.

The model used to measure the degree of publicness is based on the work of Holcombe and Sobel (1995), who developed a theoretical model and empirically tested the publicness of state legislative activities. This model is based, in part, on the median voter literature, which states that the median voter will be the decisive voter in a majority rule vote (Inman 1978). Using this model, they find that legislative activities are mostly private and have become less public over time (Holcombe and Sobel 1995). Their analysis is amenable to a study of AIDS prevention spending, which can be incorporated into the model in the place of legislative spending. Further details concerning this methodology will be discussed in section 4.3 .

\subsection{Methodology}

The methodology for this paper will follow in the footsteps of the median voter model of Bowen (1943), Downs (1957) and Black (1958). Many have utilized this framework for calculating the degree of publicness, including Borcherding and Deacon (1972), 
Bergstrom and Goodman (1973), Deno and Mehay (1987), and Langbein (2004). A measure for the degree of publicness has been calculated for goods as diverse as public school music, legislative activities, education, and many other public goods and services (King 2007). The layout of the model used in this paper is based on the work of Holcombe and Sobel (1995).

One key difference in the analysis presented here is the use of a panel data structure that includes 48 U.S. states for the years 1998 through 2007. Past studies have relied on cross-sectional analysis. For the objective of this project, the panel structure is preferable because it allows for the analysis of dynamic adjustment. In this case, I use the adjustment in AIDS prevention spending over time; this adjustment is not captured through cross-sectional analysis. Additionally, panel data allows for more variability in the data, both within states and over time, to be used in constructing parameter estimates. Past studies, such as those of Holcombe and Sobel (1995) and King (2007), use crosssectional data analysis to measure publicness.

The derivation of the model is as follows. First, the decisive voter's utility function is:

$$
\mathrm{U}_{\mathrm{i}}=\mathrm{U}_{\mathrm{i}}\left(\mathrm{x}_{\mathrm{i}}, \mathrm{a}_{\mathrm{i}}\right)
$$

where $a_{i}$ is the quantity of AIDS prevention programs consumed by the decisive voter, and $\mathrm{x}_{\mathrm{i}}$ is the amount of other goods consumed by the decisive voter. A represents the total amount of AIDS prevention programs produced, 


$$
a_{i}=\mathrm{N}^{-\mu} \mathrm{A}
$$

where $\mathrm{N}$ represents the state population. The degree of privateness is measured by $\mu$. Therefore, if $\mu=1$, this would imply that AIDS prevention is a purely private good, whereas a value of $\mu=0$ implies that AIDS prevention is a pure public good. AIDS prevention is a quasi-public good, having some private and some public characteristics, if $0<\mu<1$.

The budget constraint of the decisive voter is

$$
\mathrm{Y}_{\mathrm{i}}=\mathrm{P}_{\mathrm{X}} \mathrm{X}_{\mathrm{i}}+\mathrm{T}_{\mathrm{i}} \mathrm{P}_{\mathrm{A}} \mathrm{A}
$$

where $Y_{i}$ is voter i's disposable income, $P_{x}$ is the price of goods $X, T_{i}$ is voter i's tax share, and $\mathrm{P}_{\mathrm{A}}$ is the price per unit of AIDS prevention.

The budget constraint can be rewritten as follows:

$$
\mathrm{Y}_{\mathrm{i}}=\mathrm{P}_{\mathrm{x}} \mathrm{X}_{\mathrm{i}}+\mathrm{T}_{\mathrm{i}} \mathrm{P}_{\mathrm{A}} \mathrm{a}_{\mathrm{i}} \mathrm{N}^{\mu}
$$

Optimization will yield the following demand equation: 


$$
a_{i}=a_{i}\left(P_{x}, T_{i}, P_{A}, N, Y_{i}\right)
$$

For the initial regression results, it is assumed that $P_{x}$ and the per-unit price of AIDS prevention do not vary significantly across states. This assumption is reasonable for initial regressions but will also be tested as part of a robustness check. Assuming that $P_{x}$ and $\mathrm{P}_{\mathrm{A}}$ are the same across states, representing the different tastes across states as a vector $\mathrm{V}$, and using a constant elasticity demand function yields

$$
a_{i}=V\left(T_{i}, N^{\mu}\right)^{\alpha} Y_{i}^{\lambda}
$$

Substitution produces

$$
\mathrm{A}=\mathrm{VT}_{\mathrm{i}}^{\alpha} \mathrm{N}^{\mu(1+\alpha)} \mathrm{Y}_{\mathrm{i}}^{\lambda}
$$

or

$$
\mathrm{A}=\mathrm{VT}_{\mathrm{i}}^{\alpha} \mathrm{N}^{\rho} \mathrm{Y}_{\mathrm{i}}^{\lambda}
$$


where $\rho=\mu(1+\alpha)$. Converting the demand function into log form yields

$$
\ln \mathrm{A}=\ln \mathrm{V}+\alpha \ln \mathrm{T}_{\mathrm{i}}+\rho \ln \mathrm{N}+\lambda \ln \mathrm{Y}_{\mathrm{i}}
$$

Finally, $\mathrm{Y}_{\mathrm{i}}$ is determined through the following equation

$$
\mathrm{Y}_{\mathrm{i}}=\mathrm{Y}_{\mathrm{i}}^{*}+\mathrm{T}_{\mathrm{i}} \mathrm{G}-\mathrm{F}
$$

where $Y_{i}^{*}$ is the state's median household income, $G$ is the total of federal grants in the state in which the decisive voter lives, and $\mathrm{F}$ is the voter's federal tax liability. ${ }^{16}$

$\mathrm{T}_{\mathrm{i}}$, the median voter's tax share, is calculated as follows:

$\mathrm{T}_{\mathrm{i}}=\underline{\text { (marginal gross state tax rate }}{ }^{17} *$ median state income)

state general sales and income tax revenue ${ }^{18}$

\footnotetext{
${ }^{16}$ Median voter's federal tax liability $=$ average federal tax rate * state median income. See Holcombe and Sobel (1995) for further discussion regarding this equation.

${ }^{17}$ Note that Alaska and New Hampshire are not included in this data set (Feenberg and Rosen 1985), meaning that these two states are also excluded from the analysis presented here. The results were, however, replicated using average gross tax rates across states (excluding Alaska), and the empirical results were similar.

${ }^{18}$ State tax revenue from general sales and gross receipts and individual income taxes.
} 
Variables are also included to account for differences in voter preferences across states ( $\mathrm{V}$ in equation 9). These variables include the following: median age, percent of the population living in an urban area, and percent white. The Appendix provides a detailed description of data statistics and sources for these and other variables used in the analysis.

The median voter's demand for AIDS prevention spending is:

$\ln \mathrm{A}=\beta_{1}+\beta_{2} \ln \mathrm{T}_{\mathrm{i}}+\beta_{3} \ln \mathrm{POP}+\beta_{4} \ln \mathrm{Y}_{\mathrm{i}}+\beta_{5} \ln \mathrm{DEN}+\beta_{6} \ln \mathrm{AGE}+\beta_{7} \ln \mathrm{WHITE}$

$+\beta_{8} \ln \operatorname{lnBAN}+\varepsilon$

where $\varepsilon$ is the error term.

The above model assumed that $\mathrm{P}_{\mathrm{x}}$ and $\mathrm{P}_{\mathrm{A}}$ are the same across states. Additional regressions include a control variable for price differences across states. Mean annual wage estimates for healthcare practitioners are used for this purpose. ${ }^{19}$

Controlling for price differences across states alters the model as follows:

\footnotetext{
$\ln \mathrm{A}=\beta_{1}+\beta_{2} \ln \mathrm{T}_{\mathrm{i}}+\beta_{3} \ln \mathrm{POP}+\beta_{4} \ln \mathrm{Y}_{\mathrm{i}}+\beta_{5} \operatorname{lnDEN}+\beta_{6} \ln \mathrm{AGE}+\beta_{7} \ln \mathrm{WHITE}+(13)$

$\beta_{8} \operatorname{lnURBAN}+\beta_{9} \operatorname{lnHEALTHSAL}+\varepsilon$,

${ }^{19}$ Data obtained from the Bureau of Labor Statistics.
} 
where $\varepsilon$ is the error term.

To format the regressions in panel form, regressions are specified as follows:

$$
A_{i t}=\alpha \text { State }_{i}+\beta X_{i t}+\varepsilon_{i t}
$$

where, $\alpha$ is a vector of coefficients, State is a vector designating the 48 states in the dataset, $\beta$ is a vector of coefficients, $X$ is the vector of independent variables, and $\varepsilon$ represents the error term. As before, all variables are in natural log form.

In all regression specifications, $X$ includes the following independent variables: population density, population estimate, median age, percent white, percent urban, $\mathrm{Y}_{\mathrm{i}}$, and $\mathrm{T}_{\mathrm{i}}{ }^{20}$ The health salary variable, as mentioned previously, is included in additional regressions to control for potential price differences in the per-unit cost of AIDS prevention across states. Further, the per capita funds spent on abstinence education in each state and a dummy for whether a state offers STD and HIV education in their public school system are included as additional controls and robustness checks.

The stacked panel data, consisting of 48 cross sections over 10 years, was estimated using a variety of regression models. First, a pooled OLS model was analyzed, yielding little predictive power, indicated by the low values for r-squared. Further, the results of the Breusch-Pagan test suggest that heteroskedasticity is of concern. In light of

\footnotetext{
${ }^{20}$ All variables are defined as previously noted.
} 
this result, a weighted least squares model was used to correct for this issue, yielding results with much greater predictive value. ${ }^{21}$ Lastly, each regression specification was replicated using a random-effects model to ensure that there was no significant bias in the estimates or differences in explanatory power between the types of panel regressions used in this analysis. ${ }^{22}$

Empirical results of the weighted least squares model specifications are reported in Section 4.4.

\subsection{Empirical Results}

Equation (14) was estimated using CDC AIDS prevention data for the 1998-2007 time period for all states except Alaska and New Hampshire (as per footnote 3). ${ }^{23}$ The prevention figures used in this analysis include the following: HIV prevention community planning, HIV prevention activities, quality assurance, evaluation of major program activities, interventions, services, HIV prevention capacity building activities, collaboration and coordination with other related programs, laboratory support, and HIV/AIDS epidemiologic and behavioral surveillance. The degree of privateness, $\mu$, is computed as $\mu=\rho /(1+\alpha)=\beta_{3} /\left(1+\beta_{2}\right)$, where $\beta_{3}$ and $\beta_{2}$ represent the estimated elasticities of AIDS prevention spending with respect to population and the median

\footnotetext{
${ }^{21}$ In addition, the Akaike criterion indicate that weighted least squares is the preferred model among the models analyzed.

${ }^{22}$ Note that results for the pooled OLS model and the random-effects model are available in Appendix tables 4.3 and 4.4, respectively.

${ }^{23}$ Although CDC funding comes from the federal government monies, this figure serves as a proxy for state AIDS funding, as it is assumed that state politicians will request funding for their state's AIDS prevention program in accordance with the amount desired by constituents. Given the assumption of vote maximization by elected officials, it is in their interest to secure adequate funding for programs deemed most critical to voters.
} 
voter's tax share, respectively. The degree of publicness is then calculated as $(1-\mu)$.

Table 4.1 shows the results. 
Table 4.1: Weighted Least Squares Regression Results

\begin{tabular}{|c|c|c|c|c|c|}
\hline \multirow[t]{2}{*}{ Variable } & \multicolumn{5}{|c|}{ WLS Model Specifications } \\
\hline & (14) & (15) & (16) & (17) & (18) \\
\hline Constant & $\begin{array}{c}-\mathbf{1 2 . 7 1} * * * * \\
(.92)\end{array}$ & $\begin{array}{c}-\mathbf{2 2 . 0 6 * * * *} \\
(1.07)\end{array}$ & $\begin{array}{c}-\mathbf{1 8 . 5 5 * * * *} \\
(1.33)\end{array}$ & $\begin{array}{l}-\mathbf{- 2 3 . 3 6 * * * *} \\
(1.12)\end{array}$ & $\begin{array}{c}-19.22^{* * * *} \\
(1.42)\end{array}$ \\
\hline Tax Share $\left(T_{i}\right)$ & $\begin{array}{l}-.12 * * * * \\
(.01)\end{array}$ & $\begin{array}{c}-.10^{* * * * *} \\
(.01)\end{array}$ & $\begin{array}{l}-.14^{* * * *} \\
(.01)\end{array}$ & $\begin{array}{l}-.10 * * * * \\
(.01)\end{array}$ & $\begin{array}{l}-.15^{* * * *} \\
(.01)\end{array}$ \\
\hline Population (POP) & $\begin{array}{c}.51^{* * * *} \\
(.01)\end{array}$ & $\begin{array}{c}.54^{* * * *} \\
(.02)\end{array}$ & $\begin{array}{c}.57^{* * * *} \\
(.02)\end{array}$ & $\begin{array}{c}.54^{* * * *} \\
(.02)\end{array}$ & $\begin{array}{c}.57 * * * \\
(.02)\end{array}$ \\
\hline $\begin{array}{l}\text { Disposable } \\
\text { Income }\left(Y_{i}\right)\end{array}$ & $\begin{array}{c}.50^{* * * *} \\
(.09)\end{array}$ & $\begin{array}{c}-.57 * * * * \\
(.12)\end{array}$ & $\begin{array}{l}-.90 * * * * \\
(.12)\end{array}$ & $\begin{array}{l}-.65 * * * * \\
(.12)\end{array}$ & $\begin{array}{l}-.83^{* * * * *} \\
(.13)\end{array}$ \\
\hline $\begin{array}{l}\text { Population } \\
\text { Density (DEN) }\end{array}$ & $\begin{array}{c}.09^{* * * *} \\
(.01)\end{array}$ & $\begin{array}{c}.11^{* * * *} \\
(.01)\end{array}$ & $\begin{array}{c}.13 * * * \\
(.01)\end{array}$ & $\begin{array}{c}.12 * * * \\
(.01)\end{array}$ & $\begin{array}{c}.12^{* * * *} \\
(.01)\end{array}$ \\
\hline $\begin{array}{l}\text { Median Age } \\
\text { (AGE) }\end{array}$ & $\begin{array}{c}3.15^{* * * *} \\
(.17)\end{array}$ & $\begin{array}{c}2.34 * * * \\
(.20)\end{array}$ & $\begin{array}{l}\mathbf{1 . 8 6}^{* * * *} \\
(.22)\end{array}$ & $\begin{array}{c}2.23 * * * * \\
(.20)\end{array}$ & $\begin{array}{c}\mathbf{1 . 7 9 * * *} \\
(.20)\end{array}$ \\
\hline $\begin{array}{l}\text { Percent white } \\
\text { (WHITE) }\end{array}$ & $\begin{array}{c}-.49 * * * * \\
(.08)\end{array}$ & $\begin{array}{c}-.32 * * * * \\
(.08)\end{array}$ & $\begin{array}{c}-.42 * * * * \\
(.08)\end{array}$ & $\begin{array}{l}-.27 * * * * \\
(.08)\end{array}$ & $\begin{array}{l}-. .37 * * * \\
(.08)\end{array}$ \\
\hline $\begin{array}{l}\text { Percent Urban } \\
\text { (URBAN) }\end{array}$ & $\begin{array}{c}.58^{* * * *} \\
(.08)\end{array}$ & $\begin{array}{c}.48^{* * * *} \\
(.07)\end{array}$ & $\begin{array}{c}\mathbf{. 4 8}^{* * * *} \\
(.09)\end{array}$ & $\begin{array}{c}. \mathbf{4 6}^{* * * *} \\
(.07)\end{array}$ & $\begin{array}{c}.45^{* * * *} \\
(.10)\end{array}$ \\
\hline HEALTHSAL & --- & $\begin{array}{c}2.10 * * * \\
(.15)\end{array}$ & $\begin{array}{l}2.16 * * * \\
(.15)\end{array}$ & $\begin{array}{c}\mathbf{2 . 3 1 * * * *} \\
(.15)\end{array}$ & $\begin{array}{r}2.15^{* * * *} \\
(.15)\end{array}$ \\
\hline STD/HIV Ed & --- & --- & --- & $\begin{array}{c}-.04 * * \\
(.02)\end{array}$ & $\begin{array}{c}-.066^{* * * *} \\
(.02)\end{array}$ \\
\hline $\begin{array}{l}\text { Abs. Ed. Per Cap. } \\
\text { Calculated } \\
\text { Degree of } \\
\text { Privateness }(\mu)\end{array}$ & 0.58 & 0.60 & $\begin{array}{l}-.08 * * * \\
(.02) \\
0.66\end{array}$ & 0.60 & $\begin{array}{c}-.09 * * * \\
(.02) \\
\mathbf{0 . 6 7}\end{array}$ \\
\hline $\begin{array}{l}\text { Calculated } \\
\text { Degree of } \\
\text { Publicness }(1-\mu)\end{array}$ & 0.42 & 0.40 & 0.34 & 0.40 & 0.33 \\
\hline $\begin{array}{l}\text { Adjusted } \\
\text { R-squared }\end{array}$ & 0.95 & 0.96 & 0.96 & 0.96 & 0.97 \\
\hline
\end{tabular}

NOTES: For the coefficient estimates, standard errors are in parentheses and the asterisks indicate significance as follows: $* * *=1$ percent, $* *=5$ percent, $*=10$ percent. These regression results used 480 observations, including 48 cross-sections over 10 years. Weights are based on per-unit error variances. The reported adjusted $r$-squared is based on the weighted data. 
As Table 4.1 indicates (Equation 14), CDC AIDS prevention funding was 58 percent private and 42 percent public. $^{24}$ This result implies that there are, indeed, spillover benefits to AIDS prevention spending. In other words, more than two-fifths of AIDS prevention spending has external benefits. Another way to interpret this result is that 42 cents of every dollar spent on AIDS prevention will confer benefits to more than the individual receiving the prevention. This interpretation is consistent with the literature regarding AIDS prevention; prevention education, condom dispensing, and antiretroviral therapy are all believed to provide benefits to more than the individual receiving the prevention. Equation (15) is estimated with the addition of the health salary control variable to ensure that price differences across states are not biasing the publicness estimate. The estimate of equation (15) has much the same conclusion, with AIDS prevention spending being $60 \%$ private and $40 \%$ public. Thus, controlling for possible price differences across states resulted in little noticeable change in the measure of the degree of publicness of AIDS prevention spending. This result is unsurprising, as most public goods models assume that prices are similar across the United States.

Regressions (16), (17), and (18) are included as an additional robustness check and to ensure that the results aren't being driven by factors at the K-12 education level. Equation (16) includes the per capita spending on abstinence education in each state. Notice that the degree of publicness decreases when abstinence education is included in the regression; AIDS prevention is now calculated as $66 \%$ private and $34 \%$ public. Abstinence education is statistically significant at the one percent level, and it has the expected negative sign, indicating that money spent on abstinence education in public

\footnotetext{
${ }^{24}$ The weights used in these regressions are based on per-unit error variances.
} 
schools decreases the amount of CDC AIDS prevention funding. It is reasonable to hypothesize that these two goods would be substitutes, making these results unsurprising.

Equation (17) includes a dummy variable for STD and HIV education in K-12 public schools. This addition has little impact on the degree of publicness; AIDS prevention is now $60 \%$ private and $40 \%$ public; these results are identical to those of equation (15). STD/HIV education, which can also be understood as a substitute for CDC AIDS prevention, has the expected negative sign and is statistically significant at the five percent level.

Finally, both abstinence education spending per capita and STD/HIV education are included in equation (18). Both variables are significant at the one percent level and are still negative. The inclusion of both variables increases the privateness of AIDS prevention spending, with AIDS prevention now calculated as $67 \%$ private and $33 \%$ public. Regardless which specification was used, AIDS prevention spending always had an estimate of at least one-third public, suggesting that some elements of AIDS prevention are public in nature, yielding benefits to more than one person per unit provided.

Most of the signs of coefficient estimates in Table 4.1 are consistent with the previous literature. The median voter's tax share elasticity is negative in all regressions and is always statistically significant at the one percent level. The population elasticity is positive and statistically significant at the one percent level in all regressions. The coefficients on population density are always positive and significant at the one percent level. The income elasticity is always significant at the one percent level, though it 
changes sign (from positive to negative) when additional spending-related variables are added (i.e. health salary, abstinence education spending, and STD/HIV education). Given that these variables may be substitutes for CDC AIDS prevention spending, the inclusion of them in these specifications could lead to this result. The coefficients on median age were positive and significant in all regressions, an expected result given the life cycle hypothesis, which suggests that an older population demands more public goods (see See Bergstrom and Goodman 1973). In other words, if two individuals have the same tax share and income, we would expect to see that the older of the two would demand more public goods than the younger. A negative and statistically significant coefficient is found for the percent of the population that is white, indicating that a state with a greater percentage of minorities in their total population will spend larger sums of money on AIDS prevention. A positive coefficient is found for the percent of the population that is urban, and it is significant at the one percent level in all regression specifications.

In light of the results presented in Table 4.1, and further supported by the results of alternative regression techniques included in the Appendix, the hypothesis that AIDS prevention spending has significant public attributes is corroborated. More specifically, the degree of publicness associated with AIDS prevention was calculated as one-third or more in every specification of every model. Thus, even using the most conservative of these estimates of AIDS prevention publicness, one could argue for government funding to compensate for an underallocation of private funds for this cause. For example, if we assume that AIDS prevention is one-third public, one could argue that achieving the "optimal" funding of AIDS prevention would require government funding equal to half 
of private funding for AIDS prevention. In other words, if we accept the theory that goods with public attributes (i.e. positive externalities or spillovers) will be undersupplied by the market, one potential solution is for government to fund the public portion of the good to correct for this underallocation. ${ }^{25}$

\subsection{Conclusion}

Considering the fact that AIDS prevention programs are sponsored by countries across the world and consist largely of prevention education, a relevant question is just how public these programs are. As a corollary, if AIDS prevention programs are a purely public good or mainly public good, this provides some justification for government provision of these programs, though there exists skepticism about the efficiency of government provision. If, however, AIDS prevention programs are a pure private good or mostly private, these programs would likely be more efficiently provided in the private market. The results of this inquiry suggest that markets are relatively efficient, as AIDS prevention is more private than public in nature. The results of this paper indicate that AIDS prevention spending across states is $58-67 \%$ private and $33-42 \%$ public. While this indicates that AIDS prevention spending is more private than public, the results also reveal that there are significant spillover benefits associated with this spending. There are several implications of these results that merit further explication.

\footnotetext{
${ }^{25}$ Consider a numerical example: If private spending is $\$ 10$ billion, the government would supply $\$ 5$ billion in additional funds to overcome the shortfall created by externalities. Thus, the total spending on AIDS prevention would equal $\$ 15$ billion $(10+5)$, where the "public" portion of AIDS prevention (equal to $1 / 3$ of the total spent on AIDS prevention) is supplied by the government.
} 
First, AIDS prevention is more public than other goods that have been measured using this model. ${ }^{26}$ For instance, King (2007) found that K-12 public education is between 97 and 99 percent private. Although the results for AIDS prevention are more public than the results for goods measured in other studies, the results are still more private than one might have expected given the nature of AIDS prevention spending and the theoretical arguments offered in the literature regarding the public attributes of this spending. Second, although these findings suggest that there may be some role for the government to supplement private market spending for AIDS prevention, one must still proceed cautiously, as government failure and issues of misallocation are potential outcomes of government intervention in health care.

Finally, these results have even broader policy implications in terms of which education spending programs offer the most impact per dollar spent. In a study of public education, King (2007) found that K-12 education is almost purely private. Given that a major component of AIDS prevention spending is education, it is interesting that the results are much different than those of King (2007). Since K-12 education much more private than AIDS prevention, the larger policy implication is that a dollar spent on AIDS prevention has more impact (in terms of the number of people receiving the benefits) than a dollar spent on K-12 education. Given this interpretation, when funds are allocated toward AIDS prevention, a dollar spent on AIDS education will reach more individuals and offer wider impact than a dollar spent on K-12 education. This has important implications not only domestically but also internationally, where development efforts

\footnotetext{
${ }^{26}$ See Appendix Table 4.5 for a comparison of results with King's (2007) analysis of K-12 education and Holcombe and Sobel's (1995) analysis of legislative activities. The full results for the 2006 cross-section regressions are included in Table 4.6 of the Appendix.
} 
often focus on the provision of aid for the prevention of AIDS and other communicable diseases. 


\section{CHAPTER 5}

\section{Conclusion}

Though economists have explored a wide variety of health-related topics, the relative youth of the health economics field provides opportunities for many new avenues of research. Concepts from a variety of economic fields can also be applied to topics in health economics to make for a more detail-rich analysis of many issues in the health realm. For example, public economics offers perspective on issues related to health policy, such as the impact of bureaucracy and public goods on health outcomes. Likewise, economic development and political economy offer important insights into health intervention efforts. Once regarded as the domain of medical researchers and practitioners alone, numerous health topics are now being analyzed by economists as well.

One of the most important contributions of economics to the study of health concepts is a better understanding of why economic actors behave as they do. Economists offer a unique perspective on health issues, applying concepts of costs, benefits, and incentives to identify the likely health outcomes associated with a particular policy. The markets for health can be analyzed with many of the same tools applied to economic analysis of other markets for good or services, and the topics covered are as diverse as financing healthcare, macroeconomic impacts of health decisions, and behavioral incentives and responses of the individual. 
One issue of utmost importance in health economics is the analysis of health market failures. The case of public goods is but one example of the potential for market failure, especially when the externalities are large and free riding is difficult and costly to prevent (Samuelson 1954). Public goods, given their non-rivalry and/or nonexcludability, present unique challenges to the healthcare industry that can be further understood with thorough economic analysis.

In order to understand the market for health and the corresponding outcomes, it is essential to understand institutional economics and how the "rules of the game" shape incentives and outcomes. The incentives created by the healthcare institutions have important implications for health outcomes, both in terms of the health of patients and the efficiency of the health sector. The literature of bureaucracy is also relevant in that the unique structural characteristics of bureaucracy create incentives that can lead to perverse outcomes (Niskanen 1968). Incentives that encourage budget maximization in a bureaucratic system lacking a profit motive can result in a healthcare system that lacks efficiency and efficacy. This dissertation extends this framework, applying the concepts discussed above to the health topics of skin cancer, Female Genital Mutilation (FGM), and AIDS.

The second chapter of this dissertation addressed the skin cancer paradox, analyzing the relationship between National Cancer Institute spending and melanoma incidence. Though logic dictates that government spending directed towards skin cancer research and prevention would result in a lower incidence rate of skin cancer, the pattern observed over time is an increase in both the incidence rate and the per capita spending of the National Cancer Institute. The results of an empirical analysis of this relationship 
suggest that National Cancer Institute spending has been ineffectual, at best, and harmful, at worst. Concepts from the secondary effects literature and bureaucracy literature provide economic rationale for this paradoxical relationship. The secondary effects associated with an emphasis on safety and exaggerated reports of success in the "war on cancer" can result in miscalculation of the true costs of sun exposure and lead to more risky behavior. In addition, the incentives faced by bureaucracies are such that a policy of ineffective but ever-increasing spending contributes to these perverse outcomes. In their current form, these bureaucracies provide incentives encouraging budget maximization, and the capture of cancer bureaucracies by drug company special interests skews research incentives, resulting in more research into costly new drug treatments and less extensive exploration of alternative treatment avenues. Finally, the lack of feedback mechanisms to measure the efficiency of cancer bureaucracies creates perverse incentives that have serious implications for public policy pertaining to skin cancer prevention and research.

The third chapter of this dissertation focused on female genital mutilation (hereafter FGM), providing an economic theory for the persistence and change of FGM which was previously absent from the literature. The rational choice framework, including insights from game theory, serves as the basis for this analysis. The central argument of this chapter is that FGM is, indeed, a rational ritual. Rational choice analysis of the practice of FGM offers answers the following questions: (1) why does the practice of FGM persist? and (2) why and how does the practice of FGM change? Game theory foundations are utilized to provide a model for answering both of these important questions relevant for health and human rights. Our conclusions suggest that the practice 
of FGM persists for two reasons - institutional path dependence and identity. Institutional path dependence, due to increasing returns, means that, once adopted, FGM will often be self-reinforcing over time. Further, the practice of FGM is intertwined with the identity of those involved in the ritual, meaning that efforts to alter or curtail the practice of FGM must recognize the cost of lost identity as a crucial parameter. An examination of the methods of intervention and change in the practice supports this conclusion, lending evidence that formal laws alone are not enough to eliminate the practice of FGM. Instead, economic rationale suggests that the key for change is the creation of common knowledge around the change or cessation of the practice of FGM.

Chapter four of this dissertation estimated the degree of publicness of AIDS prevention spending using an empirical median voter demand model. The characteristics of many AIDS prevention efforts have characteristics that appear public in nature. This is especially true of the educational programs aimed at AIDS prevention, which are likely to be fairly nonrival in consumption (i.e. one person's consumption doesn't interfere with another's consumption) and nonexcludable (i.e. it is difficult to exclude individuals from consuming the good), the key attributes of a public good. The empirical estimates suggest that over one-third of AIDS prevention spending is public in nature, implying that there are significant spillover benefits associated with this spending. The broader implication of these results are that there may be some role for the government to supplement private market spending for AIDS prevention, though government failure and issues of misallocation must be taken into consideration. Finally, these results have even broader policy implications in terms of which education spending programs offer the most impact per dollar spent, indicating that a dollar spent on AIDS prevention has more 
impact (in terms of the number of people receiving the benefits) than a dollar spent on K12 education.

In sum, this dissertation provides contributions to three critical issues in the public economics of health. Contributions to existing literature include an economic explanation for the skin cancer paradox, an economic theory for the persistence and change of the FGM practice, and a measure of the publicness of AIDS prevention spending. The policy implications in these chapters offer insight into the failure of government spending initiatives related to health, how identity and institutions interact in rituals that have serious health and human rights implications, and how the public attributes of health prevention programs complicates their funding and affects their overall impact. Each of these implications impacts expected health outcomes. 


\section{References}

Abdalla, Raqiya Haji Dualeh. 1982. Sisters in Affliction: Circumcision and Infibulation of Women in Africa. London: Zed Press.

Ahmadu, Fuambai. 2000. "Rites and Wrongs: An Insider/Outsider Reflects on Power and Excision," In, B. Shell-Duncan and Y. Hernlund (eds.) Female 'circumcision' in Africa: Culture Controversy and Change. Colorado: Lynne Rienner, pp. 283-312.

Arhin-Tenkorang, Dyna and Pedro Conceição. 2003. "Beyond Communicable Disease Control: Health in the Age of Globalization," Providing Global Public Goods, February, pp. 484-516.

Akerlof, George A. and Rachel Kranton. 2000. "Economics and Identity," Quarterly Journal of Economics 105(3): 715-753.

Alexander, Antoinette. "Sun protection rises with innovation, information," Drug Store News, June 23, 2008.

Assaad, Marie Bassili. 1980. "Female Circumcision in Egypt: Social Implications, Current Research, and Prospects for Change," Studies in Family Planning 11(1): 3-16.

Baird, C. 1998. "Union-friendly legislation and union density: A Laffer curve analysis," Journal of Private Enterprise, 14 (special issue): 29-39.

Baker, A. 2002. An adolescent cover-up story: an insight into adolescent sun protection in New Zealand, MPh Thesis. University of Otago, Dunedin.

Beddingfield, F.C. 2003. "The melanoma epidemic: res ipsa loquitur," Oncologist 8(5): $459-65$.

Bergstrom, T. C., and Goodman, R. P. 1973. "Private Demand for Public Goods," American Economic Review 63 (3): 280-96.

Berlinger, G. 1999. "Health and Equity as a Primary Global Goal," Development 42: 1721.

Black, D. 1958. The Theory of Committees and Elections. Cambridge: Cambridge University Press.

Blomquist, Glenn C. 1988. The Regulation of Motor Vehicle and Traffic Safety. Boston: Kluwer Academic Publishers.

Borcherding, T. E., and Deacon, R. T. 1972. "The Demand for the Services of Non 
Federal Governments," American Economic Review 62(5): 891-901.

Bowen, H. R. 1943. "The Interpretation of Voting in the Allocation of Economic Resources," Quarterly Journal of Economics 58(1): 27-48.

Boyd, Jerry, ed. 1982. “The Cancer Letter,” The Cancer Letter Inc., 8(41): 1-8.

Brown, T.T., Quain, R.D., Troxel, A.B., and J.M. Gelfand. 2006. "The epidemiology of sunburn in the US population in 2003," Journal of the American Academy of Dermatology, 55(4), 577-83.

Buchanan, James M., "Politics, Policy, and the Pigouvian Margins." 1962. Economica 29: $17-28$.

Bureau of Labor Statistics, May 2007.

Calder, N., \& Aitken, R. 2008. "An exploratory study of the influences that compromise the sun protection of young adults," International Journal of Consumer Studies 32: 579-587.

Chesnokova, Tatyana and Rhema Vaithianathan. 2007. "The Economics of Female Genital Cutting," Mimeo.

Chirinko, Robert S., and Harper, Edward P., Jr. Spring 1993. "Buckle-Up or Slow Down?: New Estimates of Offsetting Behavior and The Effects of Automobile Safety Regulation," Journal of Policy Analysis \& Management 12: 270-296.

Clark, J.R. and Dwight R. Lee. Spring 1997. "Too Safe to Be Safe: Some Implications of Short-Run and Long-Run Rescue Laffer Curves," Eastern Economic Journal 23(2):127-137.

Coyne, Christopher J. 2007. After War: The Political Economy of Exporting Democracy. California: Stanford University Press.

Coyne, Christopher J. and Peter T. Leeson. 2009. "Media as Mechanism of Institutional Change and Reinforcement," Kyklos 62(1): 1-14.

Dalen, Hendrik. December 2005. "Who Carries the Burden of Reproductive Health and AIDS Programs? Evidence from OECD Donor Countries," Tinbergen Institute Discussion Paper.

DeJong, Jocelyn. 2006. "Capabilities, Reproductive Health and Well-Being," Journal of Development Studies 42(7): 1158-1179.

Deno, K. T., and Mehay, S. L. 1987. "Municipal Management Structure and Fiscal 
Performance: Do City Managers Make a Difference?" Southern Economic Journal 53(3): 627-42.

Denzau, Arthur and North, Douglass C. 1994. "Shared Mental Models: Ideologies and Institutions," Kyklos 47: 3-31.

Donley-Hayes, Karen. “The Darker Side of the Sun,” Dermatology Times June 1, 2008.

Dorkenoo, Efua. 1994. Cutting the Rose. Female Genital Mutilation: The Practice and its Prevention. London: Minority Rights Group.

Downs, A. 1957. An Economic Theory of Democracy. New York: Harper and Row.

El Ghissassi, F; Baan, R; Straif, K; Grosse, Y; Secretan, B; Bouvard, V; Benbrahim Tallaa, L; Guha, N; Freeman, C; Galichet, L; Cogliano, V. on behalf of the WHO International Agency for Research on Cancer Monograph Working Group. August 2009. "A review of human carcinogens-Part D: radiation," The Lancet Oncology 10(8): 751-752.

Epstein, Samuel. 2003. "The Stop Cancer Before it Starts Campaign: How to Win the Losing War Against Cancer," adapted for The Cancer Prevention Coalition from a publication in the International Journal of Health Services 32(4): 669-707.

Epstein, Samuel and Young, Quentin. 2004. "Opinion: Spinning the Losing War on Cancer," Environment News Service (ENS), Chicago, Illinois.

FAADS (Federal Assistance Award Data System).

Feenberg, D. R., and Rosen, H. S. 1985. State Personal Income and Sales Taxes: 1977 1983. NBER Working Paper No. 1631. Cambridge, Mass.: National Bureau of Economic Research.

Fellers, L. May 31, 1998. "Taxol is One of the Best Cancer Drugs Ever Discovered by the Federal Government: Why Is It Beyond Some Patients' Reach?” The Washington Post Magazine.

Fuchs, Victor. 1986. The Health Economy. Cambridge, MA: Harvard University Press.

Geller, A.C; Colditz, G; Oliveria, S; Emmons, K; Jorgensen, C; Aweh, G.N; and Frazier, A.L. June 2002. "Use of Sunscreen, Sunburning Rates, and Tanning Bed Use Among More Than 10,000 US Children and Adolescents," PEDIATRICS 109 (6): 1009-1014.

Gerbert, B; Johnston, K; Bleecker, T; McPhee, S. 1996. "Attitudes about Skin Cancer Prevention: A Qualitative Study,” Journal of Cancer Education 11(2): 96-101. 
Gruenbaum, Ellen. 2001. The Female Circumcision Controversy: An Anthropological Perspective. Pennsylvania: University of Pennsylvania Press.

. 2006. "Sexuality Issues in the Movement to Abolish Female Genital Cutting in Sudan," Medical Anthropology Quarterly 20(1): 121-138.

Harbaugh, William T., Kate Krause and Timothy R. Berry. 2001. "GARP for Kids: On the Development of Rational Choice Behavior," American Economic Review 91(5): 1539-1545.

Health Education Authority. 1997. Attitudes to Sunbathing and the Risks of Skin Cancer. Oxford University Press, London.

Henry J. Kaiser Family Foundation.

Hernlund, Ylva and Bettina Shell-Duncan. 2007. "Contingency, Context and Change: Negotiating Female Genital Cutting in The Gambia and Senegal," Africa Today 53(4): 43-57.

Holcombe, Randall G. and Russell S. Sobel. 1995. "Empirical Evidence on the Publicness of State Legislative Activities," Public Choice 83(1/2): 47-58.

Inman, R.P. 1978. “Testing political economy's 'as if' assumption: Is the median income voter really decisive?" Public Choice 33(4): 45-65.

Isa, Ab. Rahman, Rashidah Shuib and M. Shukri Othman. 1999. "The Practice of Female Circumcision among Muslims in Kelantan, Malaysia," Reproductive Health Matters 7(13): 137-144.

Johansen R. Elise B. 2007. "Experiencing Sex in Exile - Can Genitals Change their Gender?” In, Y. Hernlund and B. Shell-Duncan (eds.) Transcultural Bodies: Female Genital Cutting in Global Context. New Brunswick: Rutgers University Press, pp. 202-223.

Jones F.; Harris P.; Chrispin C. May 2000. "Catching the sun: an investigation of sunexposure and skin protective behavior," Psychology, Health and Medicine 5(2): 131-141.

Kalev, Henriette Dahan. 2004. "Cultural Rights or Human Rights: The Case of Female Genital Mutilation,” Sex Roles 51(5/6): 339-348.

Keeler, Theodore E. June 1994. "Highway Safety, Economic Behavior, and Driving Environment," American Economic Review 84: 684-693.

Kevane, Michael. 1994. “Can There Be an 'Identity Economics?’ Mimeo, Harvard Academy for International and Area Studies. 
King, Kerry. 2007. "Do Spillover Benefits Create a Market Inefficiency in K-12 Public Education?" Cato Journal 27(1): 447-458.

Koskela, Erkki \& Matti Virén, 2000. "Is there a Laffer curve between aggregate output and public sector employment?" Empirical Economics, 25(4): 605-621.

Laffer, Arthur B., June 2004. “The Laffer Curve: Past, Present, and Future,” Heritage Foundation Backgrounder No. 1765.

Lamanna, L. M. April 2004. College students' knowledge and attitudes about cancer and perceived risks of developing skin cancer. Dermatology Nursing 16: 161-164.

Langbein, L. 2004. "Public School Music: Notes on the Public Provision of a Quasi Private Good," Public Choice 121(1): 83-98.

Lee, Dwight R., Jeffrey R. Clark. 1996. "Sentencing Laffer curves, political myopia, and prison space," Social Science Quarterly 77(2): 245-55.

Lee, Dwight R., Jeffrey R. Clark. 1997. "Too safe to be safe," Eastern Economic Journal 23: $127-37$.

Leibowitz, Arleen. 2004. "The demand for health and health concerns after 30 years," Journal of Health Economics 23(4): 663-671.

Lensink, Robert and Howard White. 1999. "Is there an Aid Laffer Curve?" CREDIT Research Paper No 99/6, Nottingham: Centre for Research in Economic Development and International Trade, University of Nottingham.

Lightfoot-Klein, Hanny. 1989a. Prisoner's of Ritual: An Odyssey into Female Genital Circumcision in Africa. New York: The Haworth Press.

. 1989b. "The Sexual Experience and Marital Adjustment of Genitally Circumcised and Infibulated Females in The Sudan," The Journal of Sex Research 26(3): 375392.

Mackie, Gerry. 1996. "Ending Footbinding and Infibulation: A Convention Account," American Sociological Review 61: 999-1017.

Merck. 2005. "Female Genital Mutilation," The Merck Manuals: Online Medical Library. Available online: http://www.merck.com/mmpe/sec19/ch301/ch301b.html

Murray, C. D., \& Turner, E. 2004. "Health, risk and sunbed use: A qualitative study," Health, Risk \& Society, 6(1): 67-80.

Musgrove, Philip. 2004. Health Economics in Development. World Bank Publications: 
Human Development Network. Health, nutrition, and population series.

National Institutes of Health. "National Cancer Institute. National Cancer Advisory Board: Minutes of Meeting February 1-3, 1982." Bethesda, Maryland: NIH Campus.

. "National Cancer Institute. National Cancer Advisory Board: Minutes of Meeting May 18-20, 1981." Bethesda, Maryland: NIH Campus.

Niskanen, William A. 1968. "The Peculiar Economics of Bureaucracy," The American Economic Review 58(2): 293-305.

. 1971. Bureaucracy and Representative Government. Chicago: Aldine Atherton.

North, Douglass C. 1990. Institutions, Institutional Change and Economic Performance. New York: Cambridge University Press. . 2005. Understanding the Process of Economic Change. New Jersey: Princeton University Press.

Nussbaum, Martha C. 2000. Women and Human Development: The Capabilities Approach. Cambridge: Cambridge University Press.

Obermeyer, Caria Makhlouf and Robert F. Reynolds. 1999. "Female Genital Surgeries, Reproductive Health and Sexuality: A Review of the Evidence," Reproductive Health Matters 7(13): 112-120.

Peltzman, Sam. 1975. "The Effects of Automobile Safety Regulation,” The Journal of Political Economy 83(4): 677-726.

Peterson, Steven P., Hoffer, George E., and Millner, Edward L. October 1995. "Are Drivers of Airbag Equipped Cars More Aggressive: A Test of the Peltzman Hypotheses?" Journal of Law and Economics 38: 251-265.

Samuelson, Paul 1964. "Public goods and subscription TV: Correction of the record," Journal of Law and Economics 7: 81-83.

. 1954. "The Pure Theory of Public Expenditure," Review of Economics and Statistics 36: 387-89.

Sanderson, Lilian Passmore. 1981. Against the Mutilation of Women: The Struggle Against Unnecessary Suffering. London: Ithaca Press.

Sandler, Todd, and Daniel G. Arce M. 2002. "A Conceptual Framework for Understanding Global and Transnational Public Goods for Health," Fiscal Studies 23(2): 195-222. 
Sanyal, Amal \& Gang, Ira N \& Goswami, Omkar. 2000. "Corruption, Tax Evasion and the Laffer Curve," Public Choice 105(1-2): 61-78.

Schmaus, Warren. 1981. "Fraud and Sloppiness in Science," Perspectives on the Professions: A Periodical of the Center for the Study of Ethics in the Professions (CSEP), Illinois Institute of Technology, 1(3/4).

Schwartz, John. "FDA Panel Votes to Resume Tamoxifen Trials; Breast Cancer Study, Interrupted by Data Probe, Is Criticized Over Uterine Cancer Risk," The Washington Post 8 June 1994: A10.

Sen, Amartya. 1992. Inequality Reexamined. Oxford: Oxford University Press. . 1993. "Capability and well-being," in, A. Sen and M. Nussbaum (eds.) The Quality of Life, Oxford: Clarenden Press, pp. 30-53.

. 1999. Development as Freedom. Oxford: Oxford University Press.

Shmanske, S. 2002. "Enrollment and Curriculum : A Laffer Curve Analysis," The Journal of Economic Education, 33(1): 73-82.

Skaine, Rosemarie. 2005. Female Genital Mutilation: Legal, Cultural and Medical Issues. North Carolina: McFarland.

Sobel, Russell S. 2004. "Welfare Economics and Public Finance," in Handbook of Public Finance, Edited by Jurgen G. Backhaus and Richard E. Wagner, Kluwer Academic Publishers, pp.19-51.

Sobel, Russell S. \& Todd M. Nesbit. 2007. "Automobile Safety Regulation and the Incentive to Drive Recklessly: Evidence from NASCAR," Southern Economic Journal 74(1): 71-84.

Stroup, R. L. 1998. “The endangered species act: The Laffer curve strikes again.” Journal of Private Enterprise 14 (special issue): 48-62.

Stryker, J. E., Sulky, B.A., and Emmons, K.M. 2005. "A Content Analysis of News Coverage of Skin Cancer Prevention and Detection, 1979 to 2003," Arch Dermatol 141: 491-6.

Talle, A. 1993. 'Transforming Women into 'Pure' Agnates: Aspects of Female Infibulation in Somalia," In V. Broch-Due, I. Rudie and T. Bleie (eds.) Carved Flesh, Case Selves: Gender Symbols and Social Practices. Oxford: Berg Publishers, pp. 83-106. 
Toubia, Nahid. 1993. Female Genital Mutilation: A Call for Global Action. New York: Women, Ink.

Tullock, G. 1965. The Politics of Bureaucracy. Washington, DC: Public Affairs Press.

UNICEF. 2005a. Changing a Harmful Social Convention: Female Genital Mutilation/Cutting. Florence: Italy. .2005b. Female Genital Mutilation/Female Genital Cutting: A Statistical Report. New York: UNICEF.

United States Agency for International Development (USAID). 2000. "Egypt Demographic and Health Survey." Available online: http://www.measuredhs.com/topics/gender/FGC-CD/eg.cfm

U.S. Department of Commerce, Bureau of the Census.

Viscusi, W Kip. 1985. "Consumer Behavior and the Safety Effects of Product Safety Regulation," Journal of Law \& Economics 28(3): 527-53.

Von Mises, Ludwig. 1944. Bureaucracy. Yale University Press.

Weinstein ND. 1988. "The precaution adoption process," Health Psychol 7: 355-386.

Williamson, Oliver. 2000. "The New Institutional Economics: Taking Stock and Looking Ahead," Journal of Economic Literature 38: 595-613.

Willman, David. "Three Researchers in NIH Controversy are Leaving," The Los Angeles Times, 10 March 2005.

World Health Organization. 2008. Eliminating Female Genital Mutilation - An interagency statement. Geneva, Switzerland.

Yoder, P. Stanley, Papa Ousmane Camara and Baba Soumaoro. 1999. Female Genital Cutting and Coming of Age in Guinea. Calverton: Macro International Inc.

Yoder, P. Stanley, Noureddine Abderrahim and Arlinda Zhuzhuni. 2004. Female Genital Cutting in the Demographic and Health Surveys: A Critical and Comparative Analysis. DHS Comparative Report No. 7. Maryland: ORC Macro.

Yoder, P. Stanley and Shane Khan. 2007. Numbers of women circumcised in Africa: The production of a total. Calverton, Macro International Inc.

Yount, Kathryn M. 2004. "Symbolic Gender Politics, Religious Group Identity, and the Decline in Female Genital Cutting in Minya, Egypt," Social Forces 82(3): 10631090. 


\section{APPENDIX}

Table 2.1: Data Definitions and Sources

\begin{tabular}{|c|l|c|}
\hline Variable & \multicolumn{1}{|c|}{ Definition } & Source \\
\hline INCIDENCE & $\begin{array}{l}\text { Incidence rates (per 100,000) of invasive melanoma of the } \\
\text { skin }\end{array}$ & $\mathrm{A}$ \\
\hline INCIDENCEF & $\begin{array}{l}\text { Incidence rates (per 100,000) of invasive melanoma of the } \\
\text { skin for female population only }\end{array}$ & $\mathrm{A}$ \\
\hline INCIDENCEM & $\begin{array}{l}\text { Incidence rates (per 100,000) of invasive melanoma of the } \\
\text { skin for male population only }\end{array}$ & $\mathrm{A}$ \\
\hline NCI* & $\begin{array}{l}\text { Per capita spending (in billions of 2006\$) for National } \\
\text { Cancer Institute }\end{array}$ & $\mathrm{B}$ \\
\hline PCI & Per capita income (2006\$) & $\mathrm{C}$ \\
\hline AGE & Median age & $\mathrm{C}$ \\
\hline WHITE & Percent of U.S. population white & $\mathrm{C}$ \\
\hline
\end{tabular}

\section{Sources}

A: National Cancer Institute, SEER

B: U.S. National Institutes of Health, Office of Budget and Finance

C: U.S. Department of Commerce, Bureau of the Census

\section{Notes}

*National Cancer Institute spending includes grants for research projects and cancer centers, R\&D contracts, construction and building cancer centers, research management and support, and cancer prevention and control. 
Table 2.2: Summary Statistics, using the observations 1975 - 2004

\begin{tabular}{|c|c|c|c|c|c|}
\hline Variable & Mean & Median & Minimum & Maximum & Std. Dev. \\
\hline Incidence rate & 14.0733 & 13.7500 & 7.90000 & 20.1000 & 3.70647 \\
\hline Incidence rate $(\mathrm{M})$ & 16.8600 & 16.5000 & 8.50000 & 24.8000 & 5.17078 \\
\hline Incidence rate $(\mathrm{F})$ & 12.1267 & 12.0000 & 7.40000 & 16.9000 & 2.69289 \\
\hline NCI \$ per capita* & 11.4666 & 10.7825 & 8.29819 & 21.9957 & 2.90262 \\
\hline Per capita income* & 21320.7 & 21297.0 & 16047.0 & 26163.0 & 3100.41 \\
\hline Median age & 32.6967 & 32.8000 & 27.6000 & 37.4000 & 2.96909 \\
\hline Percent white & 28.2988 & 0.860719 & 0.804076 & 84.0000 & 39.4934 \\
\hline $\mathrm{DNCI}^{\sim}$ & 0.383148 & 0.225705 & -0.987491 & 4.50272 & 0.997400 \\
\hline DDNCI & 0.147305 & 0.0187108 & -1.01374 & 3.47189 & 0.826868 \\
\hline
\end{tabular}

*These figures were computed in thousands of real $\$$.

$\sim$ DNCI represents the first difference of the NCI \$ per capita variable. Correspondingly, DDNCI is the difference of DNCI. 
Table 2.3: Empirical Results (Using DDNCI), 1977-2004

\begin{tabular}{|c|c|c|c|}
\hline \multirow[t]{2}{*}{ Independent variable } & \multicolumn{3}{|c|}{ Coefficient estimates } \\
\hline & $\begin{array}{c}\text { Equation (1) } \\
\text { Total }\end{array}$ & $\begin{array}{c}\text { Equation (2) } \\
\text { Female }\end{array}$ & $\begin{array}{c}\text { Equation (3) } \\
\text { Male }\end{array}$ \\
\hline Constant & $\begin{array}{l}-22.157 * * * \\
(1.439)\end{array}$ & $\begin{array}{l}-13.711^{* * * *} \\
(1.262)\end{array}$ & $\begin{array}{l}-33.129 * * * \\
(1.772)\end{array}$ \\
\hline DDNCI & $\begin{array}{l}0.1037 \\
(0.1027)\end{array}$ & $\begin{array}{l}0.1201 \\
(0.0878)\end{array}$ & $\begin{array}{l}0.1282 \\
(0.1299)\end{array}$ \\
\hline PCI & $\begin{array}{l}0.0003 * * * \\
(0.0001)\end{array}$ & $\begin{array}{l}0.0002 * * \\
(0.0001)\end{array}$ & $\begin{array}{l}0.0004 * * * \\
(0.0001)\end{array}$ \\
\hline AGE & $\begin{array}{l}0.909 * * * \\
(0.103)\end{array}$ & $\begin{array}{l}0.629 * * * \\
(0.104)\end{array}$ & $\begin{array}{l}1.229 * * * \\
(0.114)\end{array}$ \\
\hline WHITE & $\begin{array}{l}0.0033 * \\
(0.0017)\end{array}$ & $\begin{array}{l}-0.0017 \\
(0.0018)\end{array}$ & $\begin{array}{l}0.0094 * * * \\
(0.0025)\end{array}$ \\
\hline Adjusted $\mathrm{R}^{2}$ & 0.9808 & 0.9685 & 0.9828 \\
\hline Observations & 28 & 28 & 28 \\
\hline
\end{tabular}

NOTES: For the coefficient estimates, standard errors are in parentheses and the asterisks indicate significance as follows: $* * *=1$ percent, $* *=5$ percent, $*=10$ percent.

Equations and Notation:

INCIDENCE $=\beta_{1}+\beta_{2} \mathrm{NCI}+\beta_{3}$ PCI $+\beta_{4}$ AGE $+\beta_{5}$ WHITE $+\varepsilon$,

where INCIDENCE is the incidence rate (per 100,000) of invasive melanoma of the skin by year of diagnosis (1975-2004). ${ }^{27} \mathrm{NCI}$ is per capita spending (in thousands of 2006 dollars) for the National Cancer Institute, which includes research project and cancer center grants, fellowships, R\&D contracts, construction and cancer center buildings, research management and support, and cancer prevention and control. This is a good proxy for prevention and research efforts because it includes per capita spending for both prevention education campaigns and the total costs of conducting research of treatment methods, capturing the real total money efforts spent per person for the cause of fighting cancer. To determine the impact of government spending on skin cancer incidence rates, it is important that any measure used represents the full costs of government efforts in this regard. Thus, this measure will be used to determine how NCI's total spending impacts the incidence rate of melanoma.

\footnotetext{
${ }^{27}$ While labeled an incidence rate, this measure could also be described as a rate of detection, as there exists no true measure of the incidence rate of any type of cancer. In addition, these estimates may be biased downward (i.e. underestimation of the true incidence rate), given past controversy related to the populations included in this measure (Boyd, ed.1982). In other words, the results implied here assume the best case scenario for the NCI's effectiveness.
} 
The regression above was then separated into the incidence rate for females and males, respectively, in the equations below.

$$
\begin{aligned}
& \text { INCIDENCEF }=\beta_{1}+\beta_{2} \mathrm{NCI}+\beta_{3} \mathrm{PCI}+\beta_{4} \mathrm{AGE}+\beta_{5} \mathrm{WHITE}+\varepsilon \\
& \mathrm{INCIDENCEM}=\beta_{1}+\beta_{2} \mathrm{NCI}+\beta_{3} \mathrm{PCI}+\beta_{4} \mathrm{AGE}+\beta_{5} \mathrm{WHITE}+\varepsilon
\end{aligned}
$$

Controls:

PCI is per capita income (in 2006 dollars), and it is included to account for the impact on melanoma incidence of additional leisure time afforded to those with a higher per capita income and, thus, more time to spend in the sun. AGE is the median age, and it is included to capture the effect of age on risky behavior and, thus, incidence rates. In general, youth is associated with greater risk-taking, and studies of sun exposure reflect this, noting an increased rate of sunburn among those in their late teens and early twenties (Brown, Quain, Troxel, \& Gelfand 2006). Finally, WHITE is the percent of the population that is Caucasian, included to account for potential differences in risky sun behavior and the biological likelihood of contracting skin cancer attributed to race. As Brown et al. (2006) note, race is one variable that predicts sunburn, thus offering insight into the contribution of race to skin cancer incidence. All variables are obtained on a yearly basis for the 1975-2004 period for the United States.

Estimation Issues:

To determine the validity of this estimation, an augmented Dickey-Fuller test (ADF test) was performed to assess whether NCI spending or the skin cancer incidence rate contained a unit root. ${ }^{28}$ These tests indicated that the skin cancer incidence rate is a stationary time series and does not contain a unit root. However, NCI spending did contain a unit root, as did the first difference of this variable. Note that the results reported above include DDNCI (the second difference of NCI) instead of NCI due to the unit root problem, though Table 4 reports the results with the simple NCI per capita measure. ${ }^{29}$

Comments on Results:

The results for the control variables are consistent with medical research regarding skin cancer. A study in the Journal of the American Academy of Dermatology reports similar results, noting that the percentage of those reporting a sunburn in the previous year increased with income level (Brown, Quain, Troxel, \& Gelfand 2006). Since those with more income can afford more leisure and luxury, they could spend more time in the sun and more resources on tanning. Additionally, this study indicated that the age range with the highest reported sunburns was the 18-24 group. Given these results, it is unsurprising that the sign on median age is positive and significant. As median age increased from $20 \mathrm{~s}$ to $30 \mathrm{~s}$, the age group reporting the highest rate of sunburn aged enough to begin reporting cases of melanoma. In other words, the group of 20-somethings in the 1970s sunburned, has now aged, and is reporting the skin cancer that developed as a result of their irresponsible sun behavior years before. This is further reasoning to support the use of a differenced variable rather than the simple level of NCI spending. Finally, it is also unsurprising that the coefficient on white population is positive and statistically significant, as those with lighter skin tone have less melanin in their skin, making them more vulnerable to the sun's rays and more prone to sunburn.

\footnotetext{
${ }^{28}$ Note that the ADF test also controls for potential autocorrelation of residuals.

${ }^{29}$ In addition to testing for unit roots, a regression including only the two key variables and a constant was performed to address the potential for reverse causality and endogeneity. This regression indicated that the skin cancer incidence rate does not significantly affect DDNCI.
} 
Table 2.4: Empirical Results (Using NCI), 1975-2004

\begin{tabular}{|c|c|c|c|}
\hline \multirow[t]{2}{*}{ Independent variable } & \multicolumn{3}{|c|}{ Coefficient estimates } \\
\hline & $\begin{array}{c}\text { Equation (1) } \\
\text { Total }\end{array}$ & $\begin{array}{l}\text { Equation (2) } \\
\text { Female }\end{array}$ & $\begin{array}{c}\text { Equation (3) } \\
\text { Male }\end{array}$ \\
\hline Constant & $\begin{array}{l}-22.430^{* * *} \\
(1.824)\end{array}$ & $\begin{array}{l}-14.515^{* * *} \\
(1.708)\end{array}$ & $\begin{array}{l}-32.953^{* * *} \\
(2.443)\end{array}$ \\
\hline $\mathrm{NCI}$ & $\begin{array}{l}0.029 \\
(0.044)\end{array}$ & $\begin{array}{l}0.024 \\
(0.042)\end{array}$ & $\begin{array}{l}0.046 \\
(0.059)\end{array}$ \\
\hline PCI & $\begin{array}{l}0.0003 * * \\
(0.0001)\end{array}$ & $\begin{array}{l}0.0002^{*} \\
(0.0001)\end{array}$ & $\begin{array}{l}0.0004 * * \\
(0.0002)\end{array}$ \\
\hline AGE & $\begin{array}{l}0.927^{* * *} \\
(0.130)\end{array}$ & $\begin{array}{l}0.667^{* * *} \\
(0.121)\end{array}$ & $\begin{array}{l}1.235^{* * *} \\
(0.174)\end{array}$ \\
\hline WHITE & $\begin{array}{l}0.0038 \\
(0.0027)\end{array}$ & $\begin{array}{l}-0.0013 \\
(0.0025)\end{array}$ & $\begin{array}{l}0.0104 * * \\
(0.0036)\end{array}$ \\
\hline $\begin{array}{l}\text { Adjusted } \mathrm{R}^{2} \\
\text { Observations }\end{array}$ & $\begin{array}{l}0.9845 \\
30\end{array}$ & $\begin{array}{l}0.9742 \\
30\end{array}$ & $\begin{array}{l}0.9857 \\
30\end{array}$ \\
\hline
\end{tabular}

NOTES: For the coefficient estimates, standard errors are in parentheses and the asterisks indicate significance as follows: $* * *=1$ percent, $* *=5$ percent, $*=10$ percent. 
Figure 2.1: Graph of Melanoma Incidence and Mortality for Population Age 20-49

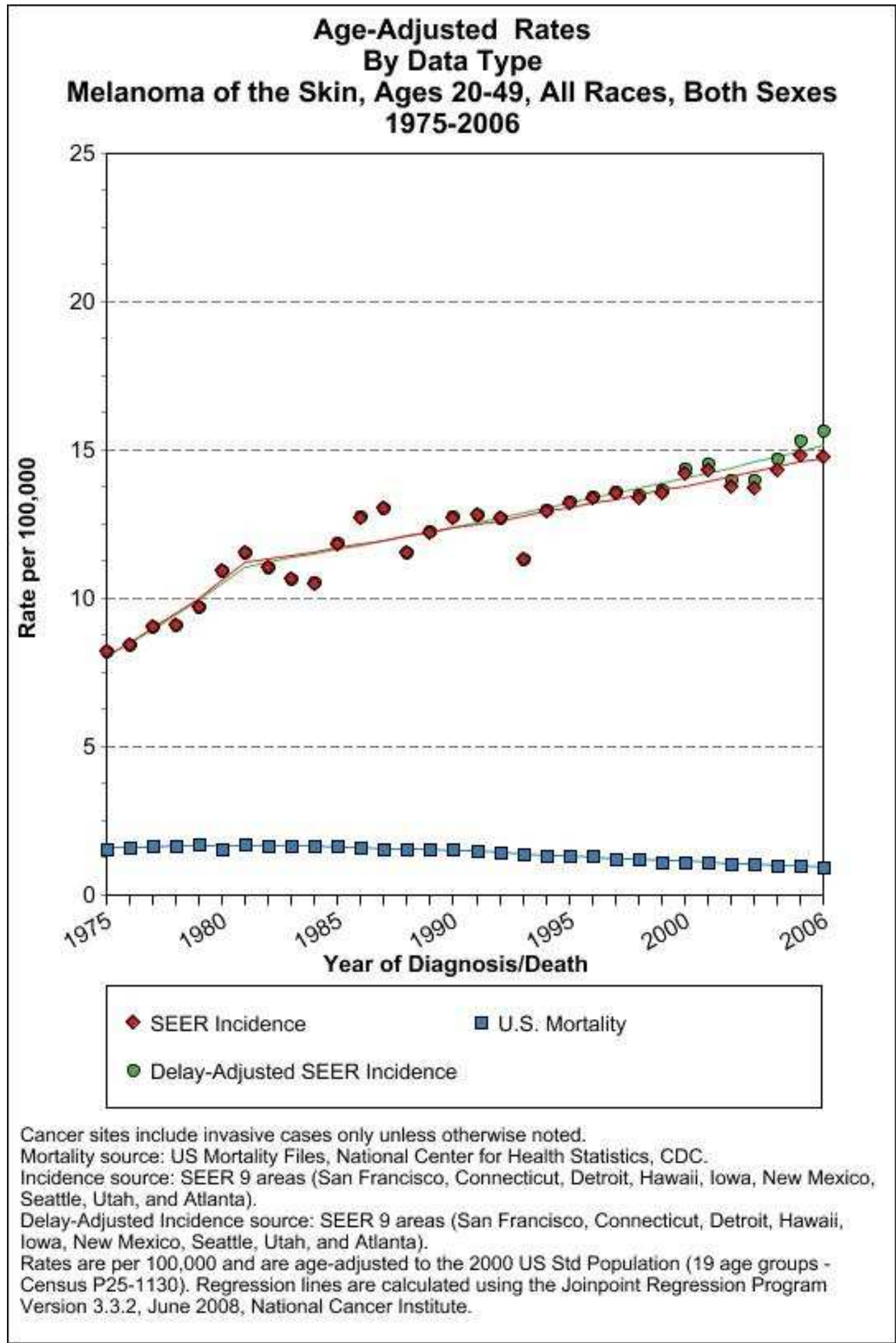


Figure 2.2: Hypotheses Explaining the Skin Cancer Paradox

\begin{tabular}{|l|l|l|l|}
\hline Hypothesis & $\mathrm{N}_{\mathrm{O}}$ [\# overexposed] $\times$ & $\begin{array}{l}\mathrm{P}_{\mathrm{D}} \text { [probability of } \\
\text { diagnosis or death] }\end{array}$ & $\begin{array}{l}\mathrm{N}_{\mathrm{D}} \text { [number of } \\
\text { diagnoses or deaths] }\end{array}$ \\
\hline Secondary Effects* & Increase & Decrease & Increase \\
\hline $\begin{array}{l}\text { Bureaucracy Effects: } \\
\text { R\&D* Effective }\end{array}$ & Increase & Decrease & Increase \\
$\begin{array}{l}\text { Case 2: Ineffective } \\
\text { R\&D }\end{array}$ & Increase & Stays the same & Increase \\
\hline
\end{tabular}

*Note the necessary condition: $\Delta \mathrm{N}_{\mathrm{O}}>\Delta \mathrm{P}_{\mathrm{D}}$. The magnitude of the increase in cases of overexposure must be greater than the magnitude of the decrease in the probability of diagnosis or death for this relationship to hold (i.e. to observe an increase in the rate of diagnoses or death). 
Table 4.1: Descriptive Statistics

\begin{tabular}{|c|c|c|c|c|c|}
\hline Variable & Obs & Mean & Std. Dev. & Min & $\operatorname{Max}$ \\
\hline stdhived & 480 & .7083333 & .4550039 & 0 & 1 \\
\hline absedpc & 480 & .6100358 & .4472414 & 0 & 2.647507 \\
\hline lncdcprevfnd & 480 & 14.95343 & .9034623 & 12.97248 & 17.68855 \\
\hline lnti & 480 & -22.30208 & 1.149656 & -25.1 & -19.9 \\
\hline lnyi & 480 & 10.53363 & .1520626 & 10.2034 & 10.84303 \\
\hline lnpop & 480 & 15.11646 & .9891257 & 13.11 & 17.34 \\
\hline Inpopden & 480 & 4.479017 & 1.291483 & 1.629241 & 7.033859 \\
\hline Inmedage & 480 & 3.610081 & .0589231 & 3.349904 & 3.7281 \\
\hline lnpwhite & 480 & 4.393057 & .1880749 & 3.372317 & 4.569741 \\
\hline Inpurban & 480 & 4.253891 & .2254218 & 3.642303 & 4.548005 \\
\hline Inhlthsal & 480 & 11.04751 & .1033107 & 10.89692 & 11.24085 \\
\hline
\end{tabular}


Table 4.2: Variable Definitions and Data Sources

\begin{tabular}{l|ll}
\hline Variable & Definition & Source \\
\hline A & $\begin{array}{ll}\text { state CDC AIDS prevention } \\
\text { expenditures }\end{array}$ & A \\
POP & Btate population & B \\
$\mathrm{Y}_{\mathrm{i}}^{*}$ & state median household & B \\
income & state population density per & B \\
DEN & square mile of land area & \\
AGE & state median age & B \\
WHITE & percent of state population & B \\
URBAN & white & \\
percent of state population & B \\
HEALTHSAL & living in an urban area & \\
& mean annual wage estimate & C \\
for healthcare practitioners & \\
F & and technical occupations & \\
\hline
\end{tabular}

\section{Sources}

A: NASTAD (National Alliance of State and Territorial AIDS Directors).

B: U.S. Department of Commerce, Bureau of the Census.

C: Bureau of Labor Statistics. (May 2007). 
Table 4.3: Pooled OLS Regression Results

\begin{tabular}{|c|c|c|c|c|c|}
\hline \multirow[t]{2}{*}{ Variable } & \multicolumn{5}{|c|}{ Pooled OLS Model Specifications } \\
\hline & (14) & (15) & (16) & (17) & (18) \\
\hline Constant & $\begin{array}{c}-12.18 * * \\
(4.82)\end{array}$ & $\begin{array}{c}-\mathbf{2 2 . 5 2} . * * * \\
(6.70)\end{array}$ & $\begin{array}{c}-18.77^{* * * *} \\
(7.04)\end{array}$ & $\begin{array}{c}-\mathbf{- 2 3 . 8 2} * * * * \\
(6.35)\end{array}$ & $\begin{array}{c}-\mathbf{2 0 . 5 2} * * * * \\
(6.55)\end{array}$ \\
\hline Tax Share $\left(T_{i}\right)$ & $\begin{array}{l}-. .08 \\
(.08)\end{array}$ & $\begin{array}{l}-. .09 \\
(.08)\end{array}$ & $\begin{array}{l}-.11 \\
.08)\end{array}$ & $\begin{array}{l}-. .08 \\
.08)\end{array}$ & $\begin{array}{l}-.11 \\
.08)\end{array}$ \\
\hline Population (POP) & $\begin{array}{l}.58 * * * \\
(.10)\end{array}$ & $\begin{array}{l}. \mathbf{5 8}^{* * * *} \\
(.10)\end{array}$ & $\begin{array}{c}. \mathbf{6 0}^{* * * *} \\
(.10)\end{array}$ & $\begin{array}{l}.59 * * * \\
(.10)\end{array}$ & $\begin{array}{c}.60 * * * \\
(.10)\end{array}$ \\
\hline $\begin{array}{l}\text { Disposable } \\
\text { Income }\left(Y_{i}\right)\end{array}$ & $\begin{array}{l}.52 \\
(.53)\end{array}$ & $\begin{array}{l}-. .54 \\
(.62)\end{array}$ & $\begin{array}{l}-.77 \\
.60)\end{array}$ & $\begin{array}{l}-. .60 \\
.63)\end{array}$ & $\begin{array}{l}-.86 \\
(.61)\end{array}$ \\
\hline $\begin{array}{l}\text { Population } \\
\text { Density (DEN) }\end{array}$ & $\begin{array}{l}. \mathbf{0 8} \\
(.05)\end{array}$ & $\begin{array}{l}\mathbf{. 0 8} \\
(.06)\end{array}$ & $\begin{array}{l}.11^{*} \\
(.06)\end{array}$ & $\begin{array}{l}.09 \\
(.06)\end{array}$ & $\begin{array}{l}.12 * * \\
(.05)\end{array}$ \\
\hline $\begin{array}{l}\text { Median Age } \\
\text { (AGE) }\end{array}$ & $\begin{array}{c}\mathbf{2 . 8 8} * * * \\
(.92)\end{array}$ & $\begin{array}{c}1.97 * * \\
(.97)\end{array}$ & $\begin{array}{l}\mathbf{1 . 4 0} \\
(.86)\end{array}$ & $\begin{array}{c}\mathbf{2 . 0 8}^{* * *} \\
(.96)\end{array}$ & $\begin{array}{l}\mathbf{1 . 4 9}^{*} \\
(.82)\end{array}$ \\
\hline $\begin{array}{l}\text { Percent white } \\
\text { (WHITE) }\end{array}$ & $\begin{array}{l}-. .43 \\
(.34)\end{array}$ & $\begin{array}{l}-. .34 \\
(.34)\end{array}$ & $\begin{array}{l}-.42 \\
(.35)\end{array}$ & $\begin{array}{l}-. .33 \\
(.34)\end{array}$ & $\begin{array}{l}-. .40 \\
(.33)\end{array}$ \\
\hline $\begin{array}{l}\text { Percent Urban } \\
\text { (URBAN) }\end{array}$ & $\begin{array}{l}.51 \\
(.44)\end{array}$ & $\begin{array}{l}.27 \\
(.40)\end{array}$ & $\begin{array}{c}. \mathbf{4 3} \\
(.37)\end{array}$ & $\begin{array}{l}.25 \\
(.40)\end{array}$ & $\begin{array}{l}.41 \\
(.37)\end{array}$ \\
\hline HEALTHSAL & --- & $\begin{array}{c}2.29 * * * \\
(.78)\end{array}$ & $\begin{array}{l}\mathbf{2 . 2 4} * * * * \\
(.78)\end{array}$ & $\begin{array}{c}\mathbf{2 . 4 3} * * * * \\
(.79)\end{array}$ & $\begin{array}{r}2.46^{* * * *} \\
(.77)\end{array}$ \\
\hline STD/HIV Ed & --- & --- & --- & $\begin{array}{l}-. .08 \\
(.08)\end{array}$ & $\begin{array}{l}-.11 \\
(.08)\end{array}$ \\
\hline $\begin{array}{l}\text { Abs. Ed. Per Cap. } \\
\text { Calculated } \\
\text { Degree of } \\
\text { Privateness }(\mu)\end{array}$ & $\begin{array}{l}--- \\
0.63\end{array}$ & $\begin{array}{l}--- \\
0.64\end{array}$ & $\begin{array}{l}\mathbf{- . 0 4} \\
(.07) \\
\mathbf{0 . 6 7}\end{array}$ & $\begin{array}{l}--- \\
0.64\end{array}$ & $\begin{array}{l}-.04 \\
(.07) \\
\mathbf{0 . 6 7}\end{array}$ \\
\hline $\begin{array}{l}\text { Calculated } \\
\text { Degree of } \\
\text { Publicness }(1-\mu)\end{array}$ & 0.37 & 0.36 & 0.33 & 0.36 & 0.33 \\
\hline $\begin{array}{l}\text { Adjusted } \\
\text { R-squared }\end{array}$ & 0.85 & 0.87 & 0.87 & 0.87 & 0.88 \\
\hline
\end{tabular}

NOTES: For the coefficient estimates, standard errors are in parentheses and the asterisks indicate significance as follows: $* * *=1$ percent, $* *=5$ percent, $*=10$ percent. These regression results used 440 observations, including 44 cross-sections over 10 years. Calculated standard errors are robust. 
Table 4.4: Random-effects Regression Results

\begin{tabular}{|c|c|c|c|c|c|}
\hline \multirow[t]{2}{*}{ Variable } & \multicolumn{5}{|c|}{ Random-effects (GLS) Model Specifications } \\
\hline & (14) & (15) & (16) & (17) & (18) \\
\hline Constant & $\begin{array}{c}\mathbf{- 1 2 . 3 4 *} \\
(6.68)\end{array}$ & $\begin{array}{c}-\mathbf{2 2 . 6 8 * * *} \\
(7.47)\end{array}$ & $\begin{array}{c}\mathbf{- 1 8 . 9 3 * *} \\
(8.03)\end{array}$ & $\begin{array}{c}-23.98 * * * \\
(7.77)\end{array}$ & $\begin{array}{c}-\mathbf{2 0 . 6 8 * *} \\
(8.27)\end{array}$ \\
\hline Tax Share $\left(\mathbf{T}_{\mathbf{i}}\right)$ & $\begin{array}{l}-.08 \\
(.09)\end{array}$ & $\begin{array}{l}-.09 \\
(.08)\end{array}$ & $\begin{array}{l}-.11 \\
(.09)\end{array}$ & $\begin{array}{l}-.08 \\
(.09)\end{array}$ & $\begin{array}{l}-.11 \\
(.09)\end{array}$ \\
\hline Population (POP) & $\begin{array}{c}.58 * * * \\
(.12)\end{array}$ & $\begin{array}{c}. \mathbf{5 8 * * *} \\
(.11)\end{array}$ & $\begin{array}{c}.60 * * * * \\
(.12)\end{array}$ & $\begin{array}{c}.59 * * * \\
(.11)\end{array}$ & $\begin{array}{l}.60 * * * \\
(.12)\end{array}$ \\
\hline $\begin{array}{l}\text { Disposable } \\
\text { Income }\left(Y_{i}\right)\end{array}$ & $\begin{array}{c}.52 \\
(.55)\end{array}$ & $\begin{array}{l}-.54 \\
(.67)\end{array}$ & $\begin{array}{l}-.77 \\
(.66)\end{array}$ & $\begin{array}{l}-.60 \\
(.68) \\
\end{array}$ & $\begin{array}{l}-.86 \\
(.67) \\
\end{array}$ \\
\hline $\begin{array}{l}\text { Population } \\
\text { Density (DEN) }\end{array}$ & $\begin{array}{c}.08 \\
(.07)\end{array}$ & $\begin{array}{c}.08 \\
(.06)\end{array}$ & $\begin{array}{c}.11 \\
(.07)\end{array}$ & $\begin{array}{c}.09 \\
(.07)\end{array}$ & $\begin{array}{c}.12 \\
(.07)\end{array}$ \\
\hline $\begin{array}{l}\text { Median Age } \\
\text { (AGE) }\end{array}$ & $\begin{array}{c}2.88 * * \\
(1.15)\end{array}$ & $\begin{array}{l}\mathbf{1 . 9 7 *} \\
(1.14)\end{array}$ & $\begin{array}{c}\mathbf{1 . 4 0} \\
(1.20) \\
\end{array}$ & $\begin{array}{l}2.08 * \\
(1.16)\end{array}$ & $\begin{array}{c}\mathbf{1 . 4 9} \\
(1.20) \\
\end{array}$ \\
\hline $\begin{array}{l}\text { Percent white } \\
\text { (WHITE) }\end{array}$ & $\begin{array}{l}-.43 \\
(.30)\end{array}$ & $\begin{array}{l}-.34 \\
(.28)\end{array}$ & $\begin{array}{l}-.42 \\
(.31)\end{array}$ & $\begin{array}{l}-.33 \\
(.29)\end{array}$ & $\begin{array}{l}-.40 \\
(.31)\end{array}$ \\
\hline $\begin{array}{l}\text { Percent Urban } \\
(\text { URBAN) }\end{array}$ & $\begin{array}{l}.51 \\
(.42)\end{array}$ & $\begin{array}{c}.27 \\
(.40)\end{array}$ & $\begin{array}{c}.43 \\
(.46)\end{array}$ & $\begin{array}{l}.26 \\
(.41)\end{array}$ & $\begin{array}{l}.41 \\
(.46)\end{array}$ \\
\hline HEALTHSAL & --- & $\begin{array}{c}2.29 * * \\
(.90)\end{array}$ & $\begin{array}{c}2.24 * * \\
(.91)\end{array}$ & $\begin{array}{c}2.43 * * * \\
(.93)\end{array}$ & $\begin{array}{r}2.46 * * * \\
(.94)\end{array}$ \\
\hline STD/HIV Ed & --- & --- & --- & $\begin{array}{l}-.08 \\
(.12)\end{array}$ & $\begin{array}{l}-.11 \\
(.12)\end{array}$ \\
\hline & $-\overline{---}$ & $\begin{array}{c}-- \\
-1\end{array}$ & $\begin{array}{l}-.04 \\
(.10)\end{array}$ & --- & $\begin{array}{l}-.04 \\
(.10)\end{array}$ \\
\hline $\begin{array}{l}\text { Calculated } \\
\text { Degree of } \\
\text { Privateness }(\boldsymbol{\mu})\end{array}$ & 0.63 & 0.64 & 0.67 & 0.64 & 0.67 \\
\hline $\begin{array}{l}\text { Calculated } \\
\text { Degree of } \\
\text { Publicness }(1-\mu)\end{array}$ & 0.37 & 0.36 & 0.33 & 0.36 & 0.33 \\
\hline
\end{tabular}

NOTES: For the coefficient estimates, standard errors are in parentheses and the asterisks indicate significance as follows: $* * *=1$ percent, $* *=5$ percent, $*=10$ percent. These regression results used 480 observations, including 48 cross-sections over 10 years. 
Table 4.5: Publicness Results Comparison

\begin{tabular}{|l|l|}
\hline \multicolumn{1}{|c|}{ Service } & \% Private \\
\hline AIDS prevention (2006)* & $71-80$ \\
\hline AIDS prevention (1997-2006) & $58-67$ \\
\hline K-12 education (1979-1980) & 95 \\
\hline K-12 education (1989-1990) & 100 \\
\hline K-12 education (1999-2000) & 94 \\
\hline Legislative Activities (1965) & $34-64$ \\
\hline Legislative Activities (1975) & $46-76$ \\
\hline Legislative Activities (1985) & $57-77$ \\
\hline
\end{tabular}

*These results are based on a cross-section regression for 2006 AIDS prevention alone to allow for a clearer comparison with King's cross-section results for K-12 education.

${ }^{\wedge}$ These results are based on weighted least squares regressions using panel data for 10 years of AIDS prevention spending. 
Table 4.6: Cross-section Regression Results

\begin{tabular}{|c|c|c|}
\hline \multirow[t]{2}{*}{ Independent variable } & \multicolumn{2}{|c|}{ Coefficient } \\
\hline & Equation (14) & Equation (15) \\
\hline Constant & $\begin{array}{l}-14.4723 * * \\
(7.1160)\end{array}$ & $\begin{array}{l}-25.1106 * * * \\
(8.3873)\end{array}$ \\
\hline Tax Share $\left(\mathrm{T}_{\mathrm{i}}\right)$ & $\begin{array}{l}-0.1280 \\
(0.2122)\end{array}$ & $\begin{array}{l}-0.0539 \\
(0.2058)\end{array}$ \\
\hline Population (POP) & $\begin{array}{l}0.6233 * * * \\
(0.2274)\end{array}$ & $\begin{array}{l}0.6857 * * * \\
(0.2195)\end{array}$ \\
\hline Disposable Income $\left(\mathrm{Y}_{\mathrm{i}}\right)$ & $\begin{array}{l}0.4225 \\
(0.6180)\end{array}$ & $\begin{array}{l}-0.5594 \\
(0.7443)\end{array}$ \\
\hline Population Density (DEN) & $\begin{array}{l}0.0765 \\
(0.0742)\end{array}$ & $\begin{array}{l}0.0564 \\
(0.0716)\end{array}$ \\
\hline Median Age (AGE) & $\begin{array}{l}3.1621^{* *} \\
(1.3770)\end{array}$ & $\begin{array}{l}2.7336^{* *} \\
(1.3319)\end{array}$ \\
\hline Percent white (WHITE) & $\begin{array}{l}-0.3946 \\
(0.3329)\end{array}$ & $\begin{array}{l}-0.2931 \\
(0.3219)\end{array}$ \\
\hline Percent Urban (URBAN) & $\begin{array}{l}0.6276 \\
(0.4956)\end{array}$ & $\begin{array}{l}0.4757 \\
(0.4792)\end{array}$ \\
\hline HEALTHSAL & & $\begin{array}{l}2.1430 * * \\
(0.9871)\end{array}$ \\
\hline $\begin{array}{l}\text { Calculated Degree of } \\
\text { Privateness }(\mu)\end{array}$ & 0.7148 & 0.7248 \\
\hline $\begin{array}{l}\text { Calculated Degree of } \\
\text { Publicness }(1-\mu)\end{array}$ & 0.2852 & 0.2752 \\
\hline Adjusted $\mathrm{R}^{2}$ & 0.8406 & 0.8542 \\
\hline Observations & 48 & 48 \\
\hline
\end{tabular}

NOTES: For the coefficient estimates, standard errors are in parentheses and the asterisks indicate significance as follows: $* * *=1$ percent, $* *=5$ percent, $*=10$ percent. Equations (14) and (15) include the same variables as equations (14) and (15) described earlier. 